OPEN ACCESS

Edited by: Carmen Villmann,

Julius Maximilian University of Würzburg, Germany

Reviewed by:

Angelo Keramidas,

The University of Queensland,

Australia

John Mihic,

University of Texas at Austin,

United States

*Correspondence:

Luis G. Aguayo

laguayo@udec.cl

${ }^{\dagger}$ Present address: Braulio Muñoz,

Department of Pharmacology and Toxicology, Indiana University School of Medicine, Indianapolis, IN, United States

Specialty section:

This article was submitted to Molecular Signaling and Pathways,

a section of the journal

Frontiers in Molecular Neuroscience

Received: 24 August 2021

Accepted: 18 October 2021

Published: 18 November 2021

Citation:

Muñoz B, Mariqueo T, Murath $P$, Peters C, Yevenes GE, Moraga-Cid G, Peoples RW and Aguayo LG (2021)

Modulatory Actions of the Glycine Receptor $\beta$ Subunit on the Positive Allosteric Modulation of Ethanol in $\alpha 2$

Containing Receptors.

Front. Mol. Neurosci. 14:763868. doi: 10.3389/fnmol.2021.763868

\section{Modulatory Actions of the Glycine Receptor $\beta$ Subunit on the Positive Allosteric Modulation of Ethanol in $\alpha 2$ Containing Receptors}

\author{
Braulio Muñoz ${ }^{1 t}$, Trinidad Mariqueo', Pablo Murath', Christian Peters', \\ Gonzalo E. Yevenes ${ }^{2}$, Gustavo Moraga-Cid ${ }^{3}$, Robert W. Peoples ${ }^{4}$ and Luis G. Aguayo ${ }^{1 *}$ \\ ${ }^{1}$ Laboratory of Neurophysiology, Department of Physiology, Universidad de Concepción, Concepción, Chile, ${ }^{2}$ Laboratory \\ of Neuropharmacology, Department of Physiology, Universidad de Concepción, Concepción, Chile, ${ }^{3}$ Department \\ of Physiology, Universidad de Concepción, Concepción, Chile, ${ }^{4}$ Department of Biomedical Sciences, Marquette University, \\ Milwaukee, WI, United States
}

Alpha1-containing glycine receptors (GlyRs) are major mediators of synaptic inhibition in the spinal cord and brain stem. Recent studies reported the presence of $\alpha 2$-containing GlyRs in other brain regions, such as nucleus accumbens and cerebral cortex. GlyR activation decreases neuronal excitability associated with sensorial information, motor control, and respiratory functions; all of which are significantly altered during ethanol intoxication. We evaluated the role of $\beta$ GlyR subunits and of two basic amino acid residues, K389 and R390, located in the large intracellular loop (IL) of the $\alpha 2$ GlyR subunit, which are important for binding and functional modulation by G $\beta \gamma$, the dimer of the trimeric $G$ protein conformation, using HEK-293 transfected cells combined with patch clamp electrophysiology. We demonstrate a new modulatory role of the $\beta$ subunit on ethanol sensitivity of $\alpha 2$ subunits. Specifically, we found a differential allosteric modulation in homomeric $\alpha 2$ GlyRs compared with the $\alpha 2 \beta$ heteromeric conformation. Indeed, while $\alpha 2$ was insensitive, $\alpha 2 \beta$ GlyRs were substantially potentiated by ethanol, GTP- $\gamma$-S, propofol, $\mathrm{Zn}^{2+}$ and trichloroethanol. Furthermore, a G $\beta \gamma$ scavenger (ct-GRK2) selectively attenuated the effects of ethanol on recombinant $\alpha 2 \beta$ GlyRs. Mutations in an $\alpha 2$ GlyR co-expressed with the $\beta$ subunit ( $\alpha 2 \mathrm{AA} \beta$ ) specifically blocked ethanol sensitivity, but not propofol potentiation. These results show a selective mechanism for low ethanol concentration effects on homomeric and heteromeric conformations of $\alpha 2$ GlyRs and provide a new mechanism for ethanol pharmacology, which is relevant to upper brain regions where $\alpha 2$ GlyRs are abundantly expressed.

Keywords: receptor pharmacology, glycine receptor, ethanol, allosteric modulation, G-protein

\section{INTRODUCTION}

Alcohol use disorder and alcoholism are major health problems affecting millions of people worldwide and causing great medical and economic burdens. Ethanol is a CNS depressant drug, and at intoxicating concentrations, it disrupts most brain functions including executive planning, awareness, muscle control, and memory (Spanagel, 2009). Inhibitory glycine receptors (GlyRs) play a central role controlling spinal and brain stem excitability 
(Legendre, 2001; Harvey et al., 2004; Lynch, 2004), and it is widely accepted that pharmacologically relevant concentrations of ethanol positively modulate $\alpha 1$ containing GlyRs (Aguayo and Pancetti, 1994; Eggers et al., 2000; Sebe et al., 2003).

More recently, it was found that GlyRs in the nucleus accumbens (nAc) might be implicated in ethanol intake and seeking behaviors (Molander and Soderpalm, 2005; Adermark et al., 2011; Li et al., 2012; Munoz et al., 2020). Accumbal neurons appear to express a mixed population of $\alpha 1$ and $\alpha 2$ subunits, however, it is largely unknown if they are equally sensitive to ethanol. Up to now, most studies that have examined the effects of ethanol on recombinant GlyRs have used homomeric conformations of $\alpha 1$ or $\alpha 2$ expressed in HEK 293 cells or oocytes (Crawford et al., 2008; Yevenes et al., 2010; McCracken et al., 2013). The studies showed that the $\alpha 2$ subunit was less sensitive to ethanol than $\alpha 1$ homomeric subunits (Yevenes et al., 2010). Furthermore, these studies indicated that although the intracellular loop (IL) molecular requirements are present in the $\alpha 2$ subunit, the channel is not a target for positive allosteric modulation by ethanol (Yevenes et al., 2010).

From the available results, we have been able to initiate our understanding on how ethanol sensitivity of the different GlyRs subunits relate to behaviors. For instance, Knock In (KI) mice with mutations in the IL of the $\alpha 1$ and $\alpha 2$ subunits showed a $30 \%$ shorter duration of loss of righting reflex (LORR) to ethanol compared to WT mice (Aguayo et al., 2014; Gallegos et al., 2021). In addition, KI mice showed higher intake of ethanol upon first exposure and greater conditioned place preference to ethanol (Munoz et al., 2020).

The present study shows that the $\beta$ subunit is a key molecular component that affects ethanol sensitivity since co-expression of $\alpha 2$ with $\beta$ subunits increased the sensitivity to low ethanol concentrations opening a new mechanistic alternative to alter the effect of ethanol in higher brain regions that express $\alpha 2 \beta$ GlyRs (Avila et al., 2013a,b). Thus, our study provides a new role for $\alpha 2$ and $\beta$ subunits and reveals a previously undefined aspect of GlyRs pharmacology.

\section{MATERIALS AND METHODS}

\section{Cell Culture and Transfection}

Human embryonic kidney (HEK) 293 cells (CRL-1573; American Type Culture Collection, Manassas, VA, United States) were cultured using standard methods. The cells were transfected using the calcium phosphate technique with $2 \mu \mathrm{g}$ of cDNA plasmids per $35 \mathrm{~mm}$ dish encoding GlyR $\alpha$ subunits and 1 $\mu \mathrm{g}$ of EGFP. To favor the formation of heteromeric GlyRs, we transfected $1 \mu \mathrm{g}$ of $\alpha$ subunits/EGFP plasmids plus $4 \mu \mathrm{g}$ of $\beta$ subunit cDNA (Yevenes et al., 2010). For the G $\beta \gamma$ sequester study, $1 \mu \mathrm{g}$ of ct-GRK2 was co-transfected with GlyR $\alpha 2$ and $\beta$ subunits. All recordings were made $18-24 \mathrm{~h}$ after transfection. The cDNA encoding the GlyRs has been described previously (Yevenes and Zeilhofer, 2011b). Residues in GlyR $\alpha 2$ (K389A and R390A) were replaced by alanine ( $\alpha 2 \mathrm{AA})$ using the QuickChange site-directed mutagenesis kit (Agilent Technologies). Proper sequences of all constructs were confirmed by full-length sequencing.

\section{For Single Channel Recordings}

HEK-293 cells were cultured to 70-95\% confluence in minimum essential medium (MEM) containing 10\% heat-inactivated donor horse serum, Earle's salts, non-essential amino acids, sodium pyruvate, and GlutaMAX (Thermo Fisher Scientific) at $37^{\circ} \mathrm{C}$ with $5 \% \mathrm{CO}_{2}$. Cells were plated in $35-\mathrm{mm}$ dishes coated with poly-D-lysine and fibronectin and transfected with cDNA for the glycine receptors $\alpha 1, \alpha 2$, or $\alpha 2 \beta$ subunits and green fluorescent protein (Addgene) using a calcium phosphate transfection kit (Thermo Fisher Scientific). The cDNA ratios were 1:5 for $\alpha 1$ : GFP, 1:10 for $\alpha 2$ : GFP, and 1:10:2.5 for $\alpha 2: \beta$ : GFP. The higher $\beta$ plasmid ratio ensured heterometric GlyR formation for recordings that were done within $48 \mathrm{~h}$ following transfection. In our single channel recordings, conductance measurements supported the presence of heteromeric $\alpha 2 \beta$ receptors with higher conductance (100 pS). In addition, previous studies showed that incorporation of $\beta$ to $\alpha 2$ subunits reduced the effects of picrotoxinoides (Fuentealba et al., 2011).

\section{Electrophysiology}

Glycine-evoked currents were recorded from transfected HEK 293 cells in the whole-cell voltage-clamp configuration at room temperature $\left(20-24^{\circ} \mathrm{C}\right)$ at a holding potential of -60 $\mathrm{mV}$ (Yevenes et al., 2010). Patch electrodes were pulled from borosilicate glass and were filled with (in $\mathrm{mM}$ ): $120 \mathrm{CsCl}, 10$ BAPTA, 10 HEPES (pH 7.4), $4 \mathrm{MgCl}_{2}, 0.5 \mathrm{GTP}$, and 2 ATP. The external solution contained (in $\mathrm{mM}$ ): $140 \mathrm{NaCl}, 5.4 \mathrm{KCl}$, 2.0 $\mathrm{CaCl}_{2}, 1.0 \mathrm{MgCl}_{2}, 10 \mathrm{HEPES}$ ( $\mathrm{pH} 7.4$ ), and 10 glucose. Whole-cell recordings were performed with an Axoclamp 200B amplifier (Molecular Devices, United States) and acquired using Clampex 10.1 software. Data analysis was performed off-line using Clampfit 10.1 (Axon Instruments, Sunnyvale, CA, United States). Exogenous glycine-evoked currents were obtained using a stepper motor-driven rapid solution exchanger (Warner Instrument Corp). The percentages of rise and decay time were obtained from whole-cell current traces of $5 \mathrm{~s}$ of duration. The $\mathrm{EC}_{10}$ values for the recombinant and neuronal receptors were obtained experimentally after the successive application of increasing concentrations of glycine $(1-1000 \mu \mathrm{M})$. The effects of ethanol or GTP- $\gamma$-S on the peak amplitude of the current were studied at an $\mathrm{EC}_{10}$ of glycine to compare the effects at equipotent concentrations. The concentrationresponse curve parameters $\left(\mathrm{EC}_{50}\right.$ and Hill coefficients, $\mathrm{n}_{\mathrm{h}}$ ) were obtained from the curve fits of normalized concentrationresponse data points to the equation $\mathrm{I}_{\text {agonist }}=\mathrm{I}_{\max }$ (agonist) ${ }^{\text {nh }}$ $/\left[(\text { agonist })^{\mathrm{nh}}+\left(\mathrm{EC}_{50}\right)^{\mathrm{nh}}\right]$. The mean maximal current $\left(\mathrm{I}_{\max }\right)$ indicated corresponds to the average maximal current elicited by saturating concentrations of the agonist. To study G $\beta \gamma$ activation, $\mathrm{G}$ proteins were activated with a non-hydrolyzable analog of GTP in the internal solution (GTP- $\gamma-\mathrm{S}, 0.5 \mathrm{mM}$, Sigma Aldrich).

The patch pipettes for single channel recordings had tip resistances of 7-15 $\mathrm{M} \Omega$ and were manually fire polished in a microforge (Narishige, Japan). In some experiments they were coated with DuPont elastomer R6101 to reduce capacitive noise. Data was acquired using pClamp software and analyzed off-line with Clampfit 10.1 (Axon Instruments, Union City, 
CA, United States). Further details were previously published (Yevenes et al., 2008, 2010). Single-channel recording was performed at room temperature using an Axopatch 200B (Molecular Devices, Sunnyvale, CA, United States) amplifier and digitized with a 1322A Digidata (Axon Instruments, Union City, CA, United States). Data were acquired at $50 \mathrm{kHz}$ and digitally low-pass filtered at $5 \mathrm{kHz}$. Outside-out patches were voltage-clamped at $-60 \mathrm{mV}$ and superfused in an external recording solution containing (in $\mathrm{mM}$ ): $150 \mathrm{NaCl}, 5 \mathrm{KCl}, 0.2$ $\mathrm{CaCl}_{2}, 10 \mathrm{HEPES}, 10$ glucose, and 10 sucrose ( $\mathrm{pH} 7.4$ ). The intracellular recording solution contained (in $\mathrm{mM}$ ): $140 \mathrm{CsCl}$, 10 EGTA, and 10 HEPES ( $\mathrm{pH}$ 7.2). Solutions of glycine and ethanol were applied to patches using a stepper motor-driven solution exchange apparatus (Warner Instruments, Hamden, CT, United States) and $600 \mu \mathrm{m}$ i.d. square glass tubing. Ethanol was alternately applied at $60 \mathrm{~s}$ intervals.

\section{Single Channel Analysis}

Data records from single-channel recordings obtained from patches with one to three open levels were idealized using the segmentation K-means algorithm in the QUB software suite (Qin, 2004). The parameters analyzed were single channel conductance; MOT, mean open time; MST, mean shut time; Po, open probability. For overall mean open times and open probabilities (Po), values reported were obtained from these idealized records using Channelab (Synaptosoft). Data were obtained from 5 to 7 patches for each receptor subunit combination tested recorded for $2 \mathrm{~min}$. Bursts were defined as openings or groups of openings that are likely to represent individual activations of the ion channel, and that were separated by shut times greater than a critical duration ( $\tau$ Crit). For burst analysis, shut time distributions were fitted with probability density functions using Channelab, and a $\tau$ Crit value that minimized the total number of misclassified events was determined for each subunit combination tested. These values were $39 \mathrm{~ms}$ for $\alpha 1$ and $90 \mathrm{~ms}$ for $\alpha 2 \beta$ receptors. Groups of openings in idealized data records were then segmented into bursts using these values in QUB, excluding any segments of data with multi-level openings. The software programs Clampfit and Channelab were then used to fit probability density functions to distributions of burst durations as well as to intraburst open and shut events. Values for intraburst mean open and shut times and intraburst Po were obtained using Channelab.

\section{Reagents}

Glycine (Sigma-Aldrich) was prepared in external solution at a stock concentration of $10 \mathrm{mM}$. Zinc chloride (Sigma-Aldrich) was prepared in $\mathrm{H}_{2} \mathrm{O}$ at a stock concentration of $10 \mathrm{mM}$. Ethanol (Merk-Millipore) and trichloroethanol was dissolved directly in the external solution. Propofol (Sigma-Aldrich) and isoflurane (Baxter) was dissolved in DMSO at a stock concentration of $100 \mathrm{mM}$ and kept at $-20^{\circ} \mathrm{C}$.

\section{Sample Size}

The target number of samples in each group for our electrophysiological experiments was determined based on findings reported in our previously published studies (Yevenes et al., 2006, 2008, 2010). Using these effect sizes and an $\alpha$-level set at 0.05 and at $80 \%$ power, we determined that 5-7 electrophysiological recordings was an appropriate sample size.

\section{Replication}

All sample sizes indicated in figures for electrophysiological experiments represent biological replicates.

\section{Data Analysis}

All data was presented as mean \pm standard error of means (SEM). The analyses were performed using two-tailed unpaired and two-tailed paired Student's $t$-tests following an F-test to confirm similar variances. Non-normally distributed data were analyzed using two-tailed Welch's tests for unpaired data. A twoway ANOVA test followed by Sidak's multiple comparisons test was performed for Figures 2B,D, 5B. The value ${ }^{*} p<0.05$ was considered statistically significant. All the statistical analysis and plots were performed with MicroCal Origin 8.0 (Northampton, MA, United States) and Prism 9.0 (GraphPad, La Jolla, CA, United States) software.

\section{RESULTS}

\section{The $\beta$ Subunit Converts $\alpha 2$ Subunits to an " $\alpha 1$-Like" Glycine Receptor With Respect to Ethanol Sensitivity}

Glycine receptors can be expressed in recombinant systems as homomeric or heteromeric complexes ( $4 \alpha$ subunits: $1 \beta$ subunit) (Yu et al., 2021; Zhu and Gouaux, 2021) and their expression can be monitored looking at changes on their properties such as time to activation and glycine affinity (Figure 1A). Figure 1B shows current traces activated by an $\mathrm{EC}_{10}$ concentration of glycine in homomeric and heteromeric GlyRs. In agreement to previous studies (Yevenes et al., 2010), this data shows that homomeric $\alpha 1$ GlyRs activate faster than the $\alpha 2$ GlyRs. Additionally, the coexpression of $\beta$ with $\alpha 2$ resulted in an $\alpha 2 \beta$ complex that displayed a faster time course for activation, thus resulting in an $\alpha 1$-like phenotype (Figure 1C). As indicated in methods, we used a high $\beta: \alpha$ plasmid ratio to ensure the assembly of heteropentameric receptors ( $4 \alpha$ subunits: $1 \beta$ subunit). Analyses of concentrationresponse relationships show that the $\alpha 2$-homomeric GlyRs display a higher $\mathrm{EC}_{50}$ than the $\alpha 1$ GlyRs. In the $\alpha 1$ GlyRs, for example, the $\mathrm{EC}_{50}$ was $40 \pm 1 \mu \mathrm{M}(n=10)$, while in $\alpha 2$ it was $86 \pm 2 \mu \mathrm{M}(p<0.001, n=10$, Figure 1E and Table 1). In addition, co-expression of the $\beta$ subunit decreased the $\mathrm{EC}_{50}$ in $\alpha 2$-containings GlyRs to $48 \pm 8 \mu \mathrm{M}(n=10)$, without significant differences in $\alpha 1 \beta$ GlyRs (Figures 1D,E and Table 1). This decrease in $\mathrm{EC}_{50}$ in $\alpha 2 \beta$ GlyRs changes some properties of the $\alpha 2$-homomeric receptor complex, thus functionally it is an $\alpha 1$-like GlyRs. Because the WT subunits display two basic residues in the IL that are important for ethanol modulation (Yevenes et al., 2010; Munoz et al., 2020), we replaced the K389 and $\mathrm{R} 390$ residues in the $\mathrm{WT} \alpha 2$ GlyR $(\alpha 2 \mathrm{AA} \beta)$ to test their role in the heteropentameric receptor (Gallegos et al., 2021). We found that the mutations did not cause large effects in the properties of 
A

$\alpha 1$ GlyR

$\alpha 1 \beta$ GlyR

$\alpha 2$ GlyR

$\alpha 2 \beta$ GlyR

$\alpha 2 A A \beta$ GlyR
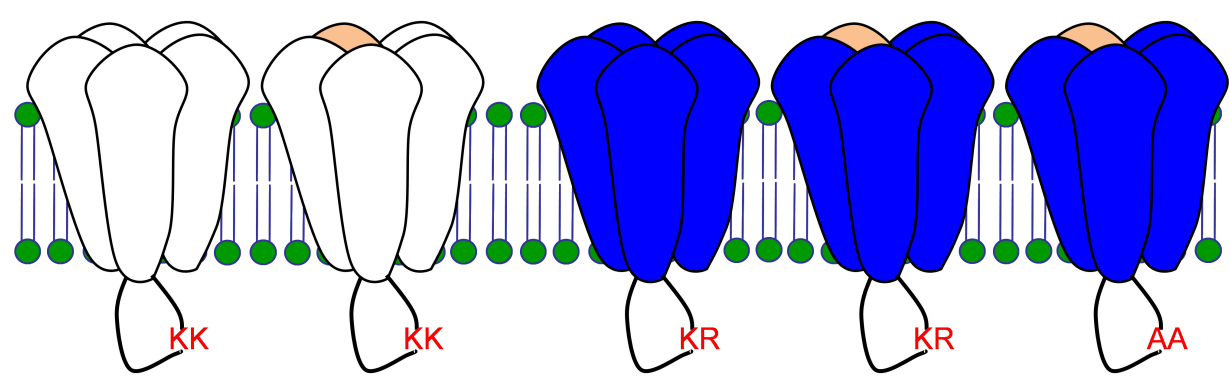

C 157

B
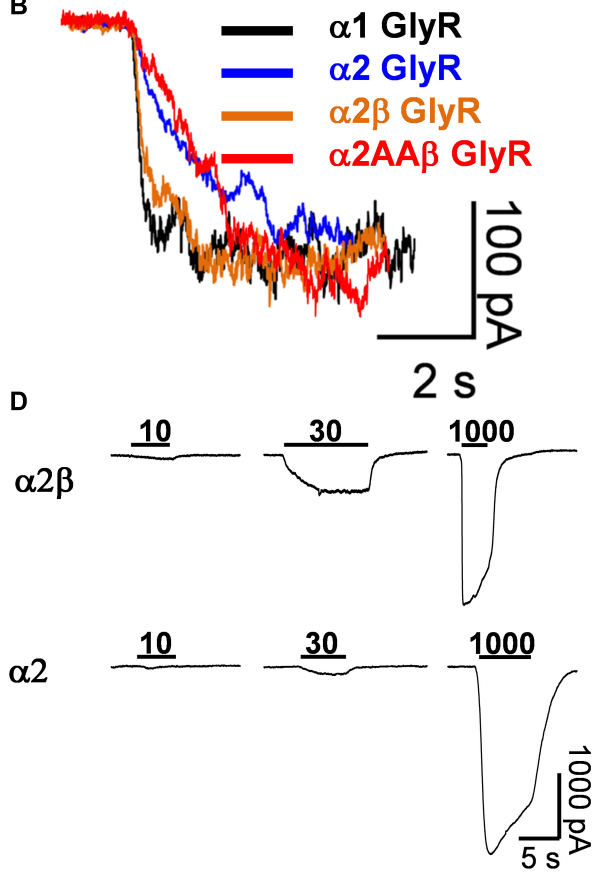

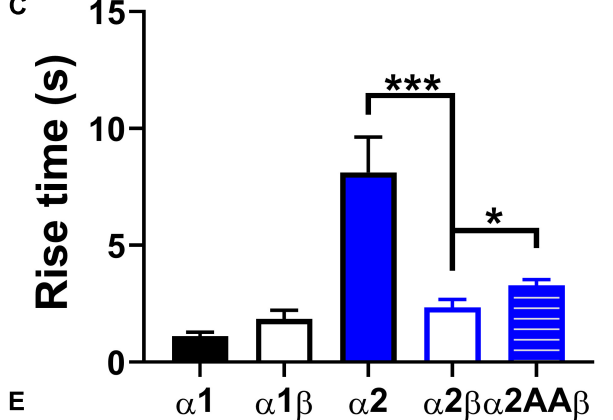

E $\quad \alpha 1 \quad \alpha 1 \beta \quad \alpha 2 \quad \alpha 2 \beta \alpha 2 A A \beta$

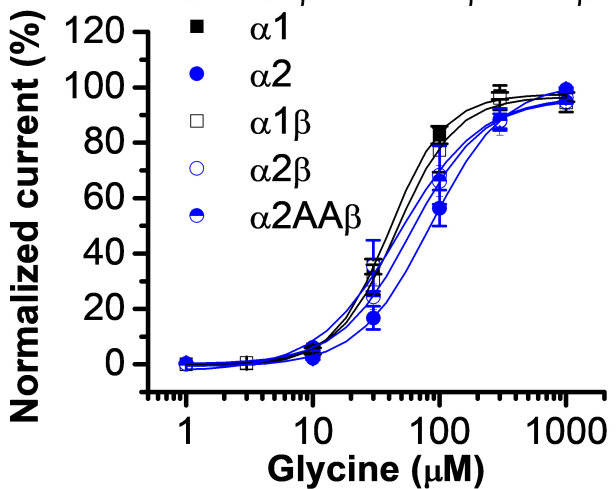

FIGURE 1 | Co-expression of $\beta$ subunits convert $\alpha 2$ GlyRs into an $\alpha 1$-like GlyRs. (A) Topology scheme of the glycine receptors used in the present study. Note that the intracellular loop in wild type $\alpha$ subunits present pairs of basic residues important for ethanol potentiation (KK or KR). (B) Representative traces of glycine-evoked currents, at $\mathrm{EC}_{10}$, showing the kinetic differences between homomeric and heteromeric GlyRs. (C) The bar graph shows the increase in rise time in $\alpha 2$ GlyRs, which is significantly reduced in heteromeric $\alpha 2 \beta$ GlyRs. (D) Representative glycine-evoked current traces showing the differences of glycine affinity between $\alpha 2$ and $\alpha 2 \beta$ GlyRs. (E) The graph shows the glycine concentration-response curve for all the GlyRs conformations. Values for $\mathrm{EC}_{50}$ can be found in Table 1. Data are mean \pm SEM. ${ }^{\star} p<0.05,{ }^{* \star *} p<0.001$. Unpaired Student's $t$ test.

TABLE 1 | Properties of whole cell currents activated by several GlyRs conformations.

\begin{tabular}{|c|c|c|c|c|c|c|c|c|}
\hline GlyR & $\mathrm{EC}_{50}(\mu \mathrm{M})$ & $\mathrm{nH}$ & $\operatorname{Imax}(p A)$ & Rise time (s) & $\begin{array}{l}10 \mathrm{mM} \text { ethanol } \\
\text { potentiation }(\%)\end{array}$ & $\begin{array}{l}100 \mathrm{mM} \text { ethanol } \\
\text { potentiation (\%) }\end{array}$ & $\begin{array}{l}\text { GTP- } \gamma \text {-S } \\
\text { potentiation (\%) }\end{array}$ & $\begin{array}{l}\text { Propofol } \\
\text { potentiation (\%) }\end{array}$ \\
\hline$\alpha 1$ & $40 \pm 1(10)$ & $1.96 \pm 0.1$ & $2111 \pm 351$ & $1.111 \pm 0.1$ & $11 \pm 3(16)$ & $46 \pm 4(16)\left(^{(\star}\right)$ & $80 \pm 10$ (ref) & $363 \pm 33$ (ref) \\
\hline$\alpha 2$ & $86 \pm 2(10)\left(^{(\star \star}\right)$ & $1.52 \pm 0.1$ & $2493 \pm 359$ & $8.116 \pm 1.5$ & $-4 \pm 4(12)$ & $12 \pm 4(12)$ & $-1 \pm 7(4)$ & $30 \pm 7(6)$ \\
\hline$\alpha 2 \beta$ & $48 \pm 8(10)\left(^{(\star \star}\right)$ & $1.5 \pm 0.1$ & $3280 \pm 471$ & $\left.2.339 \pm 0.3^{(\star \star *}\right)$ & $\left.31 \pm 7(15)^{(\star \star \star}\right)$ & $\left.90 \pm 20(15)^{(* \star}\right)$ & $73 \pm 11(10)\left({ }^{\star \star}\right)$ & $210 \pm 50(7)$ \\
\hline$\alpha 2 A A \beta$ & $60 \pm 1(12)$ & $1.5 \pm 0.03$ & $1676 \pm 276$ & $3.286 \pm 0.2\left(^{*}\right)$ & $12 \pm 7(8)$ & $10 \pm 6(8)$ & $-14 \pm 12(10)$ & $306 \pm 58(8)$ \\
\hline
\end{tabular}

Values are given as mean \pm SEM. Values were fitted to the equation I glicine $=I_{\max }[g / y c i n e]^{n \mathrm{H}} /\left([g / y c i n e]^{n \mathrm{H}}+\left[E C_{50}\right]^{n \mathrm{H}}\right)$ using Origin 8.0 software. The EC10 calculated for all subunits was used to measure rise time, decay time, ethanol and GTP- $\gamma$-S sensitivity experiment. "Ethanol potentiation" corresponds to the change between the control with glycine EC10 and presence of 10 and $100 \mathrm{mM}$ ethanol. The "GTP- $\gamma$-S potentiation" corresponds to the change after 15 minutes of dialysis of the non-hydrolyzed analog, GTP- $\gamma-S(200 \mu M)$. The "Propofol Potentiation" corresponds to the change between control with $30 \mu M$ Propofol. ND: Non determined ${ }^{*} p<0.05,{ }^{* *} p<0.01$ and ${ }^{* * *} p<0.001$, One way ANOVA $(n)=$ number of cells. 
the current (Figures 1C,E see legend for explanation of denoted residues in the IL).

Next, we tested the sensitivity of the different homomeric and heteromeric receptor conformations to ethanol using the
$\mathrm{EC}_{10-20}$ determined from the data in Table 1. The low concentration of the agonist used in this experiment is related to its property of acting as a positive allosteric modulator (PAM), where its largest effect is at $\mathrm{EC}_{10-20}$ (Aguayo et al., 1996). First,
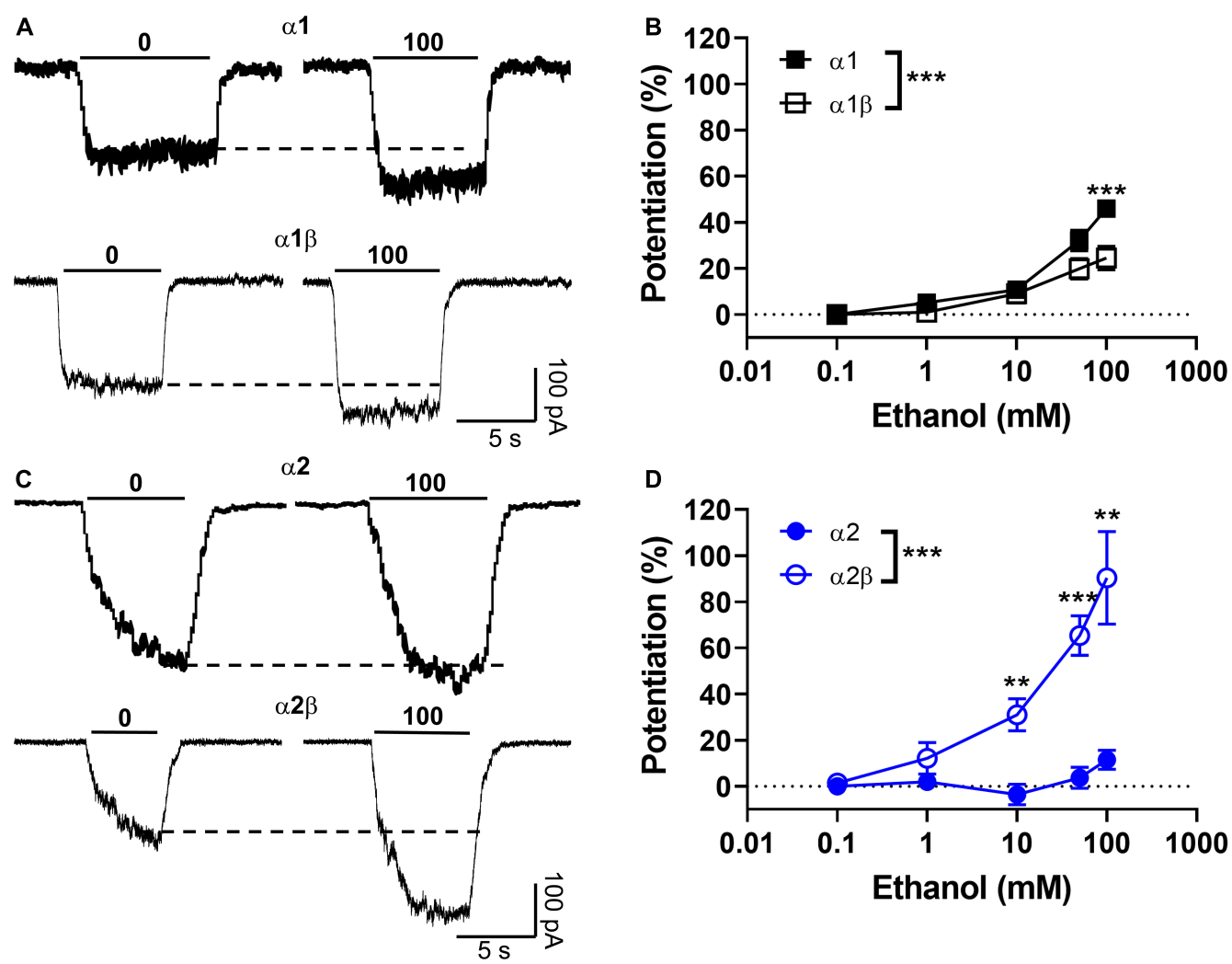

FIGURE 2 | Modulatory effects of the beta subunit on the sensitivity of $\alpha 2$-expressing GlyRs to ethanol. (A) Representative current traces recorded in HEK cells expressing homomeric $\alpha 1$ and heteromeric $\alpha 1 \beta$ GlyRs and activated with an $\mathrm{EC}_{10}$ of glycine $(15 \mu \mathrm{M})$ in presence and absence of 100 mM ethanol (by co-application). (B) The graph summarizes the effect of ethanol concentrations (0-100 mM) on $\alpha 1$ (black squares) and $\alpha 1 \beta$ (open squares) GlyRs. Data show positive ethanol modulation in both conformations, being significantly attenuated in $\alpha 1 \beta$ GlyRs $(n=16 \alpha 1$ and $n=10 \alpha 1 \beta)[P=0.0014, F(4,28)=5.941]$. (C) Representative evoked current traces recorded in homomeric $\alpha 2$ and heteromeric $\alpha 2 \beta$ GlyRs activated with an $\mathrm{EC}_{10}$ of glycine (20 $\left.\mu \mathrm{M}\right)$ with and without ethanol. (D) The graph summarizes the effect of ethanol concentrations on $\alpha 2$ (blue circles) and $\alpha 2 \beta$ (open blue circles) GlyRs. Data show positive ethanol modulation only in $\alpha 2 \beta$ GlyRs, being significant when compared with $\alpha 2(n=12 \alpha 2, n=15 \alpha 2 \beta)$. Data are mean \pm SEM. ${ }^{* *} p<0.01$, ${ }^{* \star *} p<0.001$. Two-way ANOVA and Sidak's multiple comparisons test.
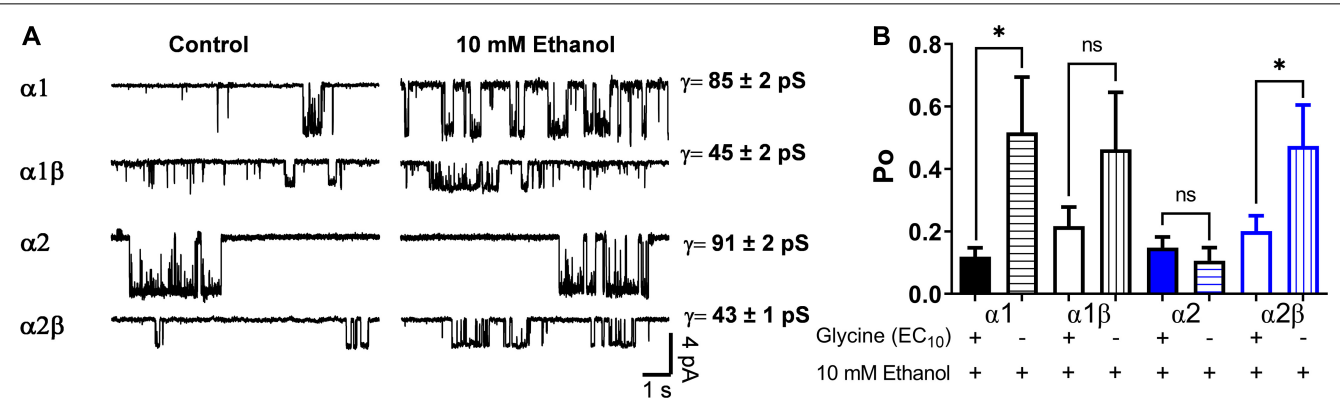

FIGURE 3 | Effects of ethanol on single channels in homomeric and heteromeric GlyRs. (A) The traces are single channel recordings obtained in transfected HEK 293 cells with different GlyRs conformations before and after the application of $10 \mathrm{mM}$ EtOH in presence of EC 10 glycine. (B) The bar graph shows the percentage of change of open probability (Po) after the application of $10 \mathrm{mM} \mathrm{EtOH}$ in homomeric and heteromeric $\alpha 1$ - and $\alpha 2$ GlyRs. The values show a decrease in heteromeric $\alpha 1 \beta$ GlyRs $(p=0.0211, \mathrm{t} 14=2.598, n=8 \alpha 1$, and $n=8 \alpha 1 \beta)$ and an increase in the open probability of $\alpha 2 \beta$ GlyRs $(p<0.0001, \mathrm{t} 13=5.98, n=8 \alpha 2$, and $n=7$ $\alpha 2 \beta)$. The single channel conductance was not affected by ethanol. Data are mean \pm SEM, ${ }^{*} p<0.05,{ }^{* * *} p<0.001$. Unpaired Student's $t$-test. ns, non significant. 
we tested the sensitivity of $\alpha 1$ homomeric GlyRs to increasing concentrations of ethanol and found that 50 and $100 \mathrm{mM}$ potentiated the peak current activated with $15 \mu \mathrm{M}$ glycine (Figures 2A,B, closed squares). The data also showed that the potentiation of glycine-mediated currents was smaller in $\alpha 1 \beta$ heteromeric GlyRs, mostly at higher ethanol concentrations (50 and $100 \mathrm{mM}$ ). For example, at $100 \mathrm{mM}$ of ethanol, the potentiation was $46 \pm 4 \%$ in $\alpha 1$ and $25 \pm 5 \%$ in the $\alpha 1 \beta$ conformer ( $p<0.001$, Figures 2A,B and Table 1). In agreement with a previous study (Yevenes et al., 2010), $\alpha 2$ homomeric GlyRs activated with $20 \mu \mathrm{M}$ glycine were insensitive to $100 \mathrm{mM}$ ethanol (12 $\pm 4 \%$, Figures 2C,D, closed circles). However, $\alpha 2 \beta$ heteromeric GlyRs showed a higher sensitivity at concentrations as low as $10 \mathrm{mM}$ ( $31 \pm 7 \%$ of control, $p=0.035$, Two-way ANOVA, Sidak's multiple comparisons test), $50 \mathrm{mM}$ (65 $\pm 9 \%$ of control, $p<0.0001$, Two-way ANOVA, Sidak's multiple comparisons test) and up to $100 \mathrm{mM}$ ethanol (90 $\pm 20 \%$ of control, $p=0.0056$, Two-way ANOVA, Sidak's multiple comparisons test, Figures $2 \mathrm{C}, \mathrm{D}$ and Table $\mathbf{1}$ ). Thus, the more significant effect of co-expressing $\beta$ with $\alpha$ subunits is the increase in sensitivity to ethanol with the $\alpha 2$ containing subunit [ethanol $\times$ GlyR subunit composition interaction: $p=0.0001$, $F(4,90)=7.271$, Two-way ANOVA] .

\section{Effect of the $\beta$ Subunit on the Action of Ethanol at the Single Channel Level}

To further characterize the effects of a low ethanol concentration (10 $\mathrm{mM})$ on the homomeric and heteromeric GlyRs conformations, we recorded single channel activity using the outside out configuration with glycine alone as control $(10 \mu \mathrm{M}$ for $\alpha 1,20 \mu \mathrm{M}$ for $\alpha 2$, and $10 \mu \mathrm{M}$ for $\alpha 2 \beta$ ) and comparing with $10 \mathrm{mM}$ ethanol in the same recording. In $\alpha 1$ homomeric GlyRs, ethanol altered the Po and frequency of opening (Figures 3A,B and Table 2). For example, open probability in $\alpha 1$ homomeric GlyRs increased by $300 \%$ above control (control: $0.12 \pm 0.03$ vs. 10 mM: $0.52 \pm 0.18 ; p<0.001$, paired $t$-test, Figures 3A,B and Table 2). The heteromeric $\alpha 1 \beta$ conformation showed a smaller increase in open probability than homomeric $\alpha 1$ subunits after ethanol application (control: $0.22 \pm 0.06$ vs. $10 \mathrm{mM}$ : $0.47 \pm 0.18$; Unpaired $t$-test, Figure $3 \mathbf{B}$ and Table 2 ). In agreement with the whole-cell results, $\alpha 2$ homomeric GlyRs showed no changes in this parameter with $10 \mathrm{mM}$ ethanol (control: $0.15 \pm 0.03$ vs.
10 mM: $0.11 \pm 0.04$; Figure 3B and Table 2). On the other hand, heteromeric $\alpha 2 \beta$ GlyRs were markedly affected by ethanol as reflected by an increase in open probability (control: $0.17 \pm 0.03$ vs. $10 \mathrm{mM}$ : $0.45 \pm 0.1 ; p<0.001$, paired $t$-test, Figures $\mathbf{3 A}, \mathbf{B}$ and Table 2). The data shows that $\beta$ subunit co-expression with $\alpha$ decreased channel conductance between homo-and heteromeric GlyRs (85-90 vs. 45 pS, respectively), and that no differences were found in the values of channel conductance in the presence of ethanol in any of the different subunit conformations (Figure 3A and Table 2).

A previous study proposed a kinetic model to explain the effects of ethanol in the $\alpha 1$ subunit (Welsh et al., 2009). Therefore, using a similar concentration of ethanol to that tested previously (Welsh et al., 2009), the effects of ethanol (100 mM) on the $\alpha 2 \beta$ conformation were analyzed (Figure 4). In homomeric $\alpha 1$ GlyRs, the results showed that this concentration of ethanol did not affect open probability (Po, $p=0.1619$, $\mathrm{t} 9=1.6$, Paired $t$-test, $n=7)$, frequency of opening $(5,483 \pm 2,323 \mathrm{ctrl}$ events vs. 7,166 $\pm 3,412$ ethanol events, $p=0.3428$, t6 $=1.03$, Paired $t$-test) and mean open time $(4.7 \pm 0.4 \mathrm{~ms}$ ctrl vs. $5.8 \pm 0.7 \mathrm{~ms}$ ethanol, $p=0.07, \mathrm{t} 6=2.198$, Paired $t$-test $)$ (Figures 4A-C). On the other hand, in $\alpha 2$ homomeric GlyRs, ethanol decreased Po $(0.3 \pm 0.09$ ctrl vs. $0.16 \pm 0.08$ ethanol, $p=0.045, \mathrm{t} 3=3.322$, Paired $t$-test) and the frequency of opening (928.3 \pm 660.8 ctrl events vs. $705.3 \pm 620.2$ ethanol events, $p=0.02, \mathrm{t} 3=4.401$, Paired $t$-test) (Figures $4 \mathrm{D}-\mathrm{F}$ ). In $\alpha 2 \beta$ receptors, however, ethanol enhanced Po $(0.11 \pm 0.05 \mathrm{ctrl}$ vs. $0.21 \pm 0.05$ ethanol, $p=0.029, \mathrm{t} 4=3.336$, Paired $t$-test) and with a tendency to increase the frequency of opening $(2,746 \pm 2,073$ ctrl events vs. $4,782 \pm 2,166$ ethanol events, $p=0.087$, $\mathrm{t} 4=2.25$, Paired $t$-test) (Figures 4G-I). Altogether, ethanol enhanced Po in both $\alpha 1(1.89 \pm 0.35)$ and $\alpha 2 \beta$, but not in $\alpha 2(\alpha 2: 0.47 \pm 0.16$ vs. $\alpha 2 \beta: 2.68 \pm 0.54$ ethanol, $p=0.0097, \mathrm{t} 7=3.519$, unpaired $t$-test) (Figure 4J). However, mean open time was not modified by ethanol (Figure $\mathbf{4 H}$ ). In addition, analysis of intraburst open probabilities showed no differences in the $\alpha 1$ and $\alpha 2 \beta$ subunit combinations $(0.70 \pm 0.040$ vs. $0.64 \pm 0.041$, respectively; $P>0.05$, two-tailed $T$ test). In $\alpha 1$ subunit glycine receptors, ethanol increased burst duration $(28 \pm 5.2$ vs. $42 \pm 2.2 \mathrm{~ms}$ for control and ethanol, respectively; $P<0.01$, paired $t$-test) without altering intraburst $\mathrm{Po}(0.70 \pm 0.040$ vs. $0.57 \pm 0.052$ for control and ethanol, respectively; $P>0.05$, paired $t$-test). In $\alpha 2 \beta$ subunit glycine receptors, ethanol did not alter burst duration $(89 \pm 15$

TABLE 2 | Effects of ethanol on the single channel properties for different conformations.

\begin{tabular}{|c|c|c|c|c|c|c|c|c|}
\hline GlyR & \multicolumn{4}{|c|}{ Control } & \multicolumn{4}{|c|}{$10 \mathrm{mM}$ ethanol } \\
\hline$\alpha 1 \beta$ & $0.22 \pm 0.06$ & $45 \pm 2$ & $56 \pm 8$ & 8 & $0.47 \pm 0.18$ & $47 \pm 1$ & $64 \pm 10^{\left({ }^{\star *}\right)}$ & 8 \\
\hline$\alpha 2$ & $0.15 \pm 0.03$ & $91 \pm 2$ & $37 \pm 11$ & 8 & $0.11 \pm 0.04$ & $89 \pm 1$ & $44 \pm 14$ & 8 \\
\hline$\alpha 2 \beta$ & $0.17 \pm 0.03$ & $43 \pm 1$ & $58 \pm 14$ & 7 & $0.45 \pm 0.1^{(\star \star)}$ & $44 \pm 1$ & $79 \pm 11\left(^{\star}\right)$ & 7 \\
\hline
\end{tabular}

Values are given as mean $\pm S E M$. The $E C_{10}$ calculated for all subunits was used for out side out ethanol sensitivity recordings ( $60 \mathrm{mV}$ ). Absolute values were statistically analyzed using the paired t-test. ${ }^{*} p<0.05,{ }^{* *} p<0.01,{ }^{* *} p<0.001$. Below $p<0.05$ was statistically significant comparing with $10 \mathrm{mM}$ Ethanol. $n=$ (number of cells). 


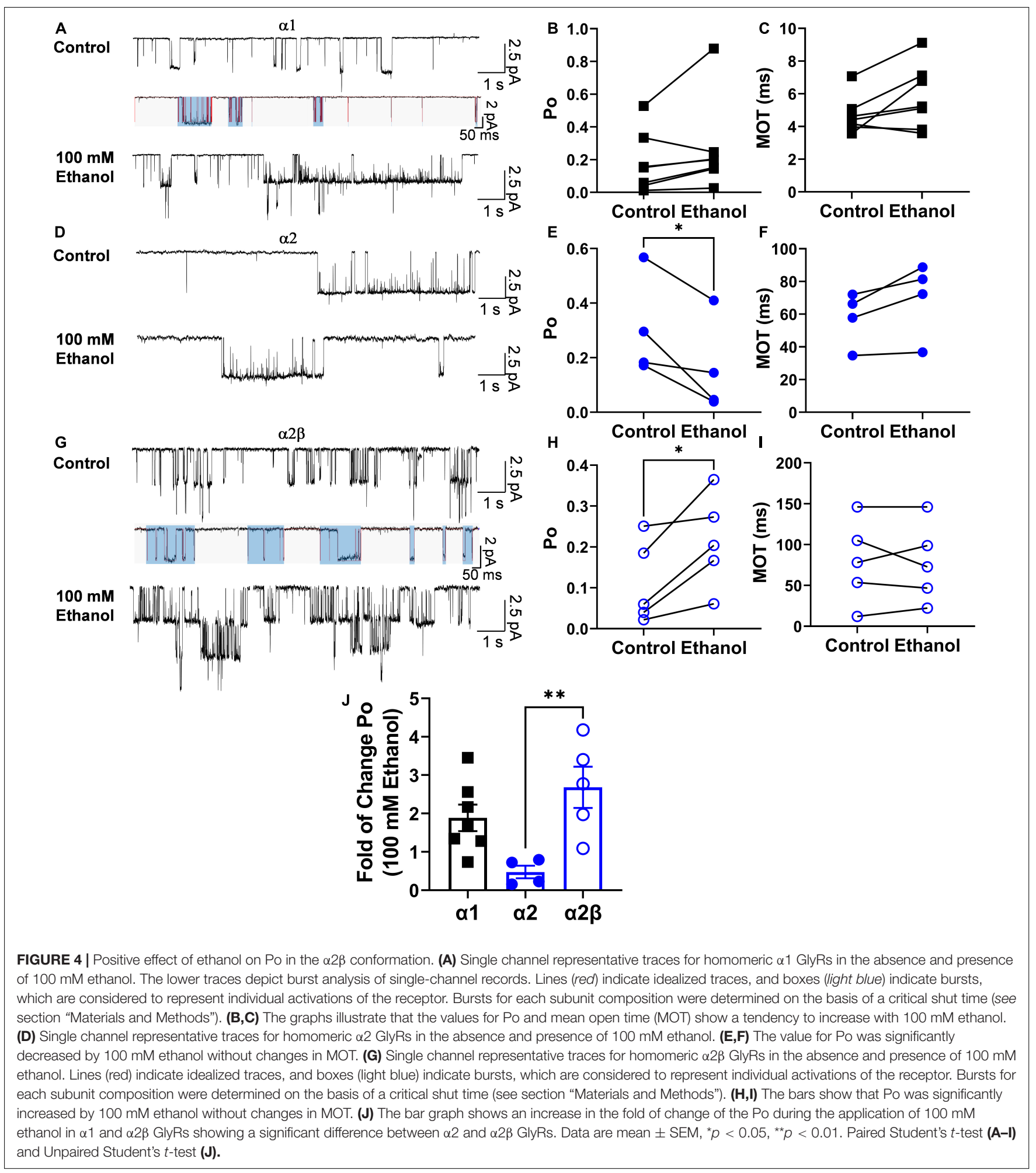

vs. $66 \pm 12 \mathrm{~ms}$ for control and ethanol, respectively; $P>0.05$, paired $t$-test $)$ or intraburst Po $(0.64 \pm 0.041$ vs. $0.69 \pm 0.019$ for control and ethanol, respectively; $P>0.05$, paired $t$-test). Although the addition of the $\beta$ subunit to the $\alpha 2$ GlyR conferred ethanol sensitivity similar to that seen in $\alpha 1$ GlyRs, the kinetics of the $\alpha 2 \beta$ GlyR nevertheless differed from those of the $\alpha 1$ GlyR. For example, while open probability within individual receptor activations (bursts) was similar, burst duration and intraburst mean open and shut times differed considerably between $\alpha 1$ and $\alpha 2 \beta$ GlyRs (Table 3). 
TABLE 3 | GlyR Burst Analysis.

\begin{tabular}{|c|c|c|c|c|c|c|c|c|c|}
\hline \multirow[b]{2}{*}{ GlyR } & \multicolumn{4}{|c|}{ Intraburst open times } & \multicolumn{3}{|c|}{ Intraburst shut times } & \multirow[b]{2}{*}{$\begin{array}{l}\text { Mean burst } \\
\text { length (ms) }\end{array}$} & \multirow[b]{2}{*}{ Intraburst $P_{0}$} \\
\hline & $\begin{array}{r}\tau_{1}(\mathrm{~ms}) \\
\text { (Area) }\end{array}$ & $\begin{array}{c}\tau_{2}(\mathrm{~ms}) \\
\text { (Area) }\end{array}$ & $\begin{array}{r}\tau_{3}(\mathrm{~ms}) \\
\text { (Area) }\end{array}$ & Mean (ms) & $\begin{array}{r}\tau_{1}(\mathrm{~ms}) \\
\text { (Area) }\end{array}$ & $\begin{array}{r}\tau_{2}(\mathrm{~ms}) \\
\text { (Area) }\end{array}$ & Mean (ms) & & \\
\hline$\alpha_{1}$ & $\begin{array}{l}0.48 \pm 0.076 \\
(35 \pm 2.3)\end{array}$ & $\begin{array}{l}2.7 \pm 0.35 \\
(46 \pm 3.2)\end{array}$ & $\begin{array}{l}15 \pm 2.0 \\
(20 \pm 2.6)\end{array}$ & $4.6 \pm 0.58$ & $\begin{array}{l}0.50 \pm 0.045 \\
(77 \pm 3.6)\end{array}$ & $\begin{array}{l}4.2 \pm 2.1 \\
(9.7 \pm 1.8)\end{array}$ & $2.5 \pm 0.27$ & $27.5 \pm 5.24$ & $0.70 \pm 0.040$ \\
\hline$\alpha 2 \beta$ & $\begin{array}{l}0.31 \pm 0.12 \\
(26 \pm 5.7)\end{array}$ & $\begin{array}{l}4.4 \pm 2.1 \\
(31 \pm 10)\end{array}$ & $\begin{array}{l}20 \pm 1.7 \\
(51 \pm 12)\end{array}$ & $13 \pm 2.3^{\star \star}$ & $\begin{array}{l}0.20 \pm 0.0020 \\
(27 \pm 4.2)\end{array}$ & $\begin{array}{l}2.6 \pm 0.63 \\
(54 \pm 9.9)\end{array}$ & $9.3 \pm 2.6^{\star}$ & $88.8 \pm 14.6^{\star \star}$ & $0.64 \pm 0.041$ \\
\hline
\end{tabular}

${ }^{\star} P<0.05,{ }^{\star *} P<0.01$; two-tailed T-test. $n=6$ and 4 cells for $\alpha 1$ and $\alpha 2 \beta$, respectivelly.

\section{The Effects of Ethanol on $\alpha 2 \beta$ Glycine Receptors Is Mediated by a G $\beta \gamma$-Linked Mechanism}

Previous reports using neuronal and recombinant $\alpha 1$ GlyRs showed that the amplitude of the glycine-activated current was strongly enhanced after $15 \mathrm{~min}$ of intracellular dialysis with GTP- $\gamma$-S, implying that G $\beta \gamma$ enhances GlyRs activity (Yevenes et al., 2003, 2010). To investigate the dependency of $G$ protein activation on the potentiation of $\alpha 2 \beta$ GlyRs by ethanol, we transfected $\alpha 2$ in different subunit conformations in HEK 293 cells. The data showed that after $15 \mathrm{~min}$ of intracellular dialysis, a large current enhancement was found in $\alpha 2 \beta$ heteromeric GlyRs $(73 \pm 11 \%)$, but not in $\alpha 2$ homomeric GlyRs $(-1 \pm 7 \%$, $p=0.0013, F(3,15)=5.03$, Two-way ANOVA, Sidak's multiple comparisons test; Figures 5A,B and Table 1). Therefore, the data indicates that the $\beta$ subunit confers the properties for $G$ protein modulation. Thus, these data demonstrate the importance of $\mathrm{G} \beta \gamma$ signaling for the ethanol effects on $\alpha 2$ GlyRs. Employing a widely used approach to examine the involvement of $G \beta \gamma$, we expressed a $G \beta \gamma$ scavenger protein, ct-GRK2, that binds with high affinity to this dimer (Yevenes et al., 2003, 2008). Cells transfected with ct-GRK2 should not be potentiated by ethanol because ct-GRK2 binds "free" G $\beta \gamma$ and prevents its interaction with effectors. Overexpression of ct-GRK2 in an independent experiment show a significant attenuation of the potentiation induced by $100 \mathrm{mM}$ ethanol in $\alpha 2 \beta$ GlyRs (control: $100 \pm 13 \%$ vs. ct-GRK2: $10 \pm 5 \%$; $p<0.001, \mathrm{t} 7=7.313$, Unpaired $t$-test, Figures 5C,D) strongly indicating that the $\mathrm{G} \beta \gamma$ signaling is critical for ethanol effects on $\alpha 2 \beta$-containing GlyRs.

It was previously reported that the $\alpha 2$ subunit has the molecular determinants in the intracellular domain necessary for allosteric modulation of GlyRs via activation of G $\beta \gamma$ (Yevenes et al., 2010). Here, two basic amino acids (K389 and R390) in the large intracellular loop of the $\alpha 2$ GlyRs subunit were detected and they were homologous to residues present in the $\alpha 1$ GlyRs subunit (K385 and K386) that are critical for binding and functional modulation by ethanol and $G \beta \gamma$ (Yevenes et al., 2006, 2008, 2010). In this study, we found that changing these two basic amino acids to alanine in $\alpha 2$ and co-expressing the mutant with the $\beta$ subunit decreased the $\mathrm{EC}_{50}$ value compared to $\alpha 2$ homomeric GlyRs ( $p<0.001$, Figure 1E and Table 1). More interesting, the mutation abolished the ethanol-induced potentiation present in $\alpha 2 \beta$ heteromeric GlyRs $(90 \pm 20 \%$ vs. $10 \pm 6 \%, p=0.001$, t20 $=3.86$, Unpaired $t$-test with Welch's correction) (Figures 6A-C and Table 1). Single channel recordings confirmed that the mutation of these two residues in $\alpha 2$ conferred resistance against low ethanol concentration effects (Po control: $0.16 \pm 0.06$ vs. Po $10 \mathrm{mM}$ : $0.14 \pm 0.06$; Figures 6D,E and Table 2), being significantly reduced compared with the naïve $\alpha 2$ subunit ( $143 \pm 27 \%$ vs. $6.6 \pm 33 \%, p=0.098$, t15 $=2.957$, Unpaired $t$-test, Figure 6E). Mechanistically, the activation of G-protein after 15 min of intracellular dialysis with GTP- $\gamma$-S showed that the $\alpha 2$ AA mutation in the intracellular loop conferred resistance to potentiation by $\mathrm{G} \beta \gamma$ when co-transfected with the $\beta$ subunit $(73 \pm 11 \%$ vs. $-11 \pm 11 \%, p<0.001$, t18 $=5.239$, Unpaired $t$-test; Figures $6 \mathbf{F}-\mathbf{H}$ and Table $\mathbf{1}$ ). Thus, these results support the idea that these two residues and the $\beta$ subunit are important for $\alpha 2$ GlyR modulation by ethanol.

\section{Beta Subunits Affect the Pharmacology of $\alpha 2$ Glycine Receptors to Positive Allosteric Modulators}

Several studies have reported different molecular sites in transmembrane 2 and 3 (TM2 and TM3) within the $\alpha 1$ subunit that are important for the actions of ethanol and other allosteric modulators (Mascia et al., 1996, 2000; Mihic et al., 1997; Lobo et al., 2004; Borghese et al., 2012). Furthermore, several PAMs differentially affect homomeric $\alpha 1$ and $\alpha 2$ GlyRs (Yevenes and Zeilhofer, 2011b). Therefore, we wanted to characterize whether the incorporation of the $\beta$ subunit affected the modulation to some typical PAMs in $\alpha 2$ GlyRs. The data show that $\alpha 2$ homomeric GlyRs are inhibited by the applications of $\mathrm{Zn}^{2+}$, isoflurane, and trichloroethanol (Figures 7A,B). The data also show that the $\beta$ subunit causes a reversal from inhibition to potentiation of the $\alpha 2 \beta$ complexes in presence of trichloroethanol $(\alpha 2:-29 \pm 5 \%$ vs. $\alpha 2 \beta: 60 \pm 24 \% ; p=0.0005, \mathrm{t} 21=4.152, n=13$ $\alpha 2$, and $n=10 \alpha 2 \beta$, Figures 7A,B $)$ and $\mathrm{Zn}^{2+}(\alpha 2:-10 \pm 13 \%$ vs. $\alpha 2 \beta: 44 \pm 17 \% ; p=0.0151, \mathrm{t} 21=2.647, n=13 \alpha 2$, and $n=10 \alpha 2 \beta$, Figures 7A,B). The finding that isoflurane was unable to produce a potentiating action in $\alpha 2$ and $\alpha 2 \beta$ supports the notion that $\alpha 2$ containing GlyRs are not molecular targets for this PAM $(\alpha 2$ : $-24 \pm 9 \%$ vs. $\alpha 2 \beta$ : $0 \pm 10 \% ; p=0.0879$, t20 = 1.794, $n=13 \alpha 2$, and $n=9 \alpha 2 \beta$, Figures 7A,B). Another classical PAM is propofol, which has been shown to potentiate $\alpha 1$-mediated GlyRs currents (Moraga-Cid et al., 2011) and to modulate glycinergic synaptic transmission in medium spiny neurons (MSNs) in the nAc (Munoz et al., 2018). In addition, a single phenylalanine residue (F380 in IL) was found to be critical on this effect in $\alpha 1$ GlyRs (Moraga-Cid et al., 2011). Our data show that $\alpha 2$ homomeric GlyRs were potentiated to a small extent by propofol $(30 \pm 7 \%$ 

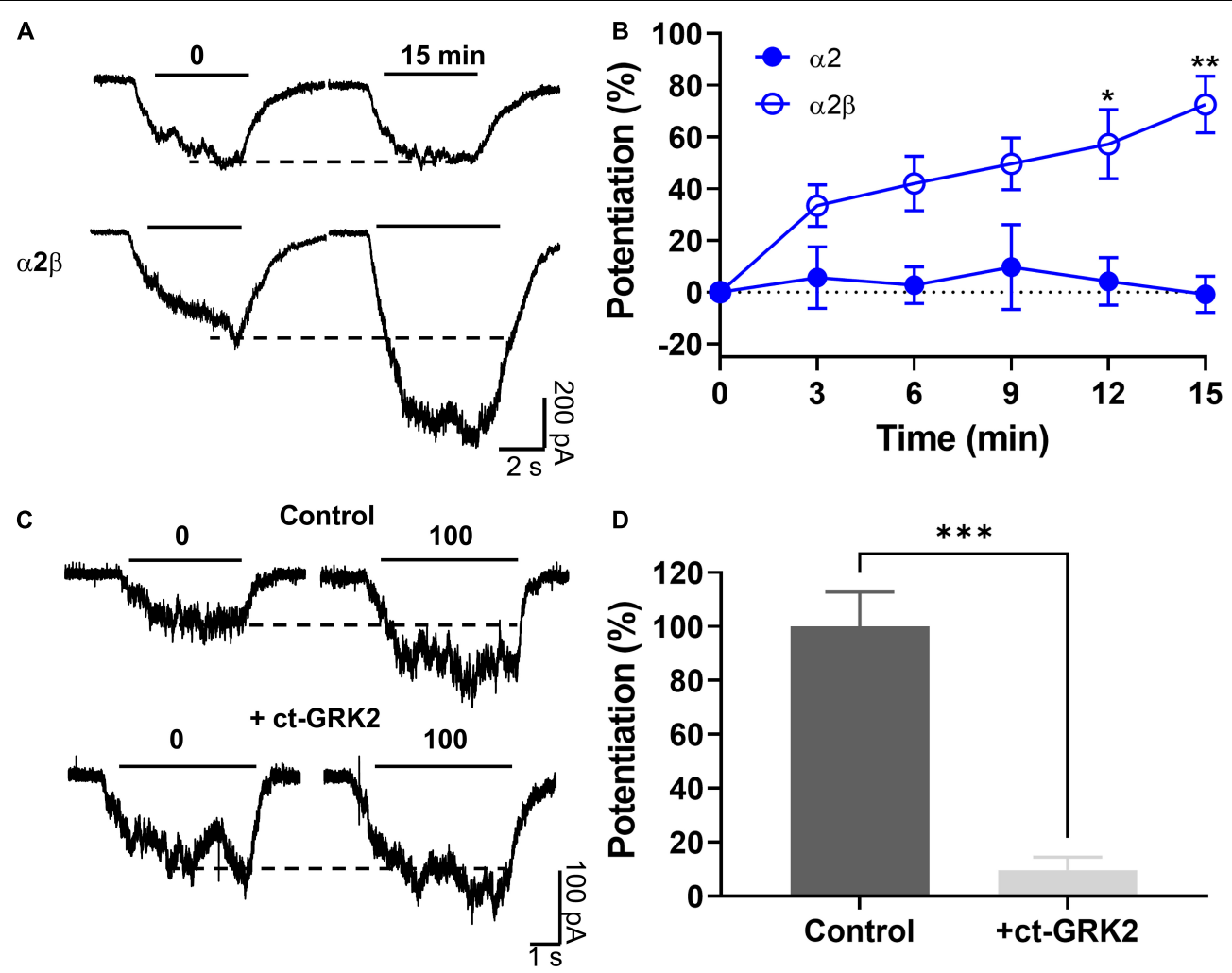

FIGURE 5 | The ethanol induced potentiation in $\alpha 2 \beta$ GlyRs was mediated by a G $\beta \gamma$-linked mechanism. (A,B) Representative evoked current traces from $\alpha 2$ and $\alpha 2 \beta$ conformations showing the effects of G-protein activation by intracellular dialysis of GTP- $\gamma-\mathrm{S}(0.2 \mathrm{mM})$ for 15 min. The time course graph summarizes the effects of G-protein activation by GTP- $\gamma$-S in $\alpha 2$ (closed blue circles) and $\alpha 2 \beta$ (open blue circles). A significant potentiation was found only in $\alpha 2 \beta$ GlyRs. (C) Current traces from HEK 293 cells transfected with $\alpha 2 \beta$ GlyRs, with or without the co-expression of the G $\beta \gamma$ scavenger ct-GRK2. (D) The graph summarizes the percentage potentiation elicited by $100 \mathrm{mM}$ ethanol on $\alpha 2 \beta$ GlyRs in the absence or presence of ct-GRK2 in an independent experiment. Data are mean \pm SEM. ${ }^{*} p<0.05$, ${ }^{* *} p<0.01$, and ${ }^{* \star *} p<0.001$. Two-way ANOVA and Sldak's multiple comparisons test (B) and Unpaired Student's $t$-test (D).

of control) (Figure 7D and Table 1), whereas both $\alpha 2 \beta$ naive and its mutant version ( $\alpha 2 \mathrm{AA}$ ) were significantly potentiated by the modulator as compared to $\alpha 2$ GlyRs $(\alpha 2 \beta: 210 \pm 50 \%, \alpha 2 \mathrm{AA} \beta$ : $306 \pm 58 \% ; \alpha 2$ vs. $\alpha 2 \beta, p<0.0001, \mathrm{t} 11=9.613, n=6 \alpha 2$ and $n=7 \alpha 2 \beta, \alpha 2$ vs. $\alpha 2 \mathrm{AA} \beta, p=0.0009, \mathrm{t} 12=4.094, n=8 \alpha 2 \mathrm{AA} \beta$, Figures 7 C,D and Table 1 ). Thus, the data suggest that the $\beta$ subunit can exert critical sensitivity to several PAMs in an $\alpha 2$ expressing channel.

\section{DISCUSSION}

\section{A New Modulatory Role for $\beta$ Subunits in the Function of Glycine Receptors}

The present study provides new information about a previously unrecognized role of the $\beta$ subunit in the allosteric modulation of GlyRs by an important group of depressants, i.e., ethanol and general anesthetics. Additionally, it provides evidence for the critical role of basic residues present in the IL of the $\alpha 2$ subunit on its functional modulation by $\mathrm{G} \beta \gamma$ and ethanol. Furthermore, the present data support the conclusion that GlyRs expressing $\alpha 2 \beta$ are one of the most sensitive brain targets for ethanol allosteric modulation.
Classically, the $\beta$ subunit of GlyRs has been widely understood to act as a structural component in the receptor because it does not present the molecular requirement for glycine binding and $\mathrm{Cl}^{-}$ion permeation (Grudzinska et al., 2005; Weltzien et al., 2012). The $\beta$ subunit contributes to GlyR physiology reducing single channel conductance (Table 2), affects the pharmacology of the GlyR complex (Table 1), and has a key role in the generation of startle disease (James et al., 2013; Piro et al., 2021). Together with $\alpha$ subunits, the $\beta$ subunit forms heteropentameric receptors having all the properties of native receptors, i.e., highly selective to its natural agonist, inhibited by strychnine, and modulated by several PAMs such as $\mathrm{Zn}^{2+}$, propofol, and ethanol (Yevenes and Zeilhofer, 2011a). Also, together with a peripheral protein (gephyrin), the $\beta$ subunit has a receptor anchoring function that localizes the GlyRs to the postsynaptic region (Grudzinska et al., 2005; Zeilhofer et al., 2005; Weltzien et al., 2012). Heteromeric GlyRs, however, have also been found at extrasynaptic locations where they mediate tonic glycinergic inhibition in the spinal dorsal horn (Gradwell et al., 2017), supporting a structural and anchoring role in sensorial pathways. Because $\alpha 2 \beta$ heteromeric conformations are found in the central nervous system (Forstera et al., 2017), it is likely that they contribute to the effect of ethanol on the tonic current induced by 

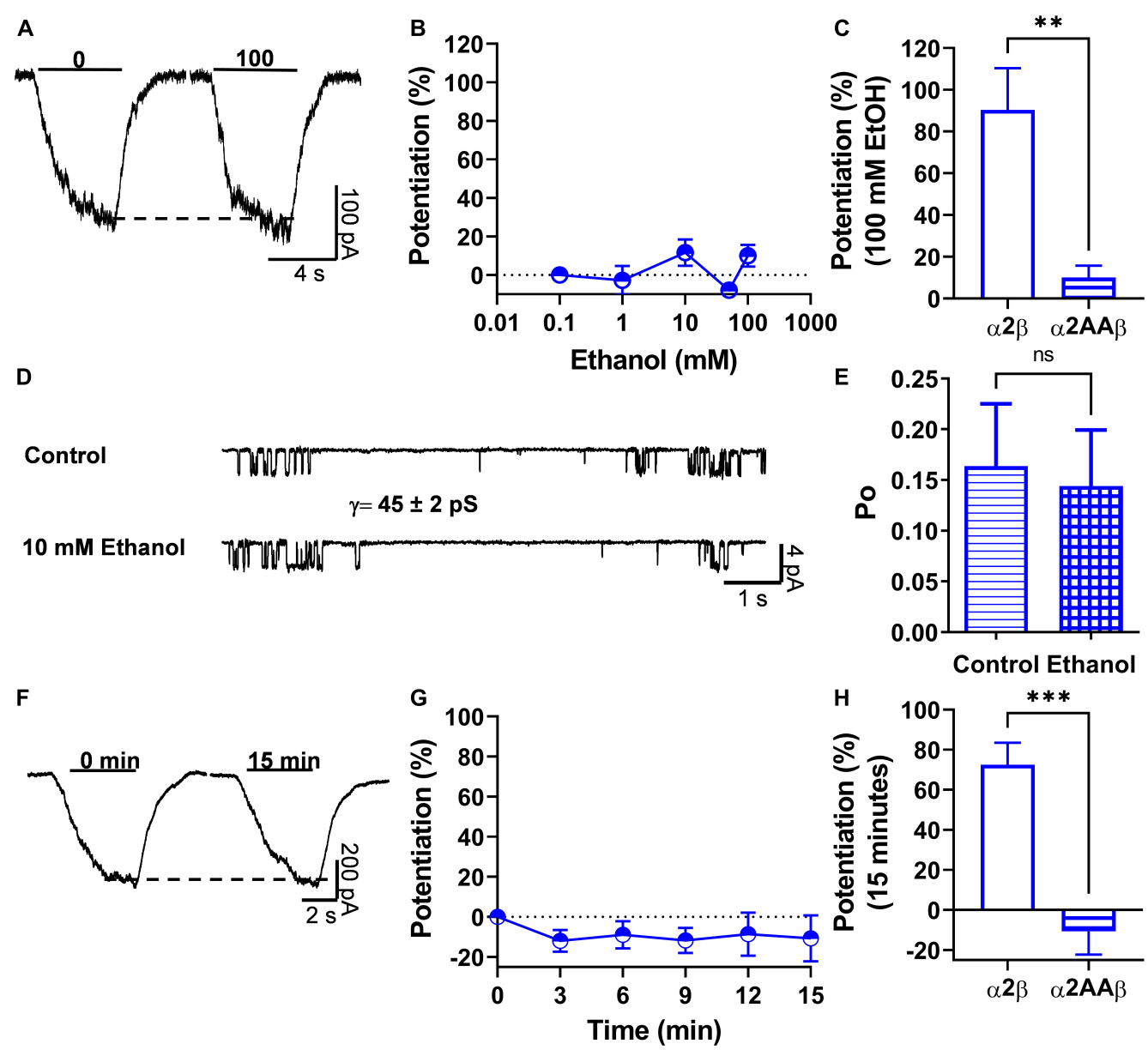

FIGURE 6 | Two basic residues in the IL of $\alpha 2$ subunits are important for G $\beta \gamma$-ethanol mediated effects. (A) Representative evoked current traces from heteromeric $\alpha 2 \mathrm{AA} \beta$ GlyRs showing the effects of $100 \mathrm{mM}$ ethanol measured with an $\mathrm{EC}_{10}$ of glycine $(20 \mu \mathrm{M})$. (B) The graph summarizes the effect of several ethanol concentrations on $\alpha 2 \mathrm{AA} \beta$ (half open blue circles) GlyRs. Data showed that ethanol did not potentiate $\alpha 2 \mathrm{AA} \beta$ GlyRs $(n=8)$. (C) Bar graph showing the potentiating effect of $100 \mathrm{mM}$ ethanol on the peak amplitude of the glycine-activated current in heteromeric $\alpha 2 \beta$ GlyRs and the introduced mutation in $\alpha 2$ that makes the heteromeric GlyRs resistant to ethanol. (D) Single channel recordings from transfected HEK 293 cells with $\alpha 2 A A \beta$ GlyRs before and after the application of 10 mM $\mathrm{EtOH}$. (E) The bar graph shows the change of open probability (Po) after the application of $10 \mathrm{mM} \mathrm{EtOH}$ in heteromeric $\alpha 2 A A \beta$ GlyRs. The values show an increase in Po in heteromeric $\alpha 2 \beta$ GlyRs. This increase was blocked with the AA mutation in the KR residues present in the IL. (F,G) Representative evoked current traces from $\alpha 2 A A \beta$ showing the effects of G-protein activation by intracellular dialysis of GTP- $\gamma-\mathrm{S}(0.2 \mathrm{mM})$ for $15 \mathrm{~min}$. The time course graph summarizes the effects of G-protein activation by GTP- $\gamma$-S in $\alpha 2 A A \beta$ (half open blue circles). (H) Bar graph summarizes the effects of G-protein activation after 15 min showing the potentiation of the glycine evoked current in $\alpha 2 \beta$ GlyRs. Data are mean \pm SEM. ${ }^{\star *} p<0.01,{ }^{\star \star \star} p<0.001$, ns, non significant. Unpaired Student's $t$-test with Welch's correction (C), Unpaired Student's t-test (E,H)

glycine in the nucleus accumbens (Munoz et al., 2020). However, the homomeric $\alpha 2$ GlyR was found to be insensitive to ethanol (Sanchez et al., 2015).

The present study provides functional evidence supporting a modulatory role for $\alpha 2$ containing GlyRs. For example, we found that co-expression of the $\beta$ subunit in heteromeric GlyRs makes the $\alpha 2 \beta$ configuration more sensitive to glycine (Table 1), ethanol, and to several pharmacologically relevant PAMs. Furthermore, mutation of two amino acids in the IL that were suggested to be related to $\mathrm{G} \beta \gamma$ binding and modulation of $\alpha 1$ subunits (Yevenes et al., 2010) abolished the potentiation of the $\alpha 2 \beta$ GlyRs by ethanol and GTP- $\gamma$-S. Additionally, coexpression of ct-GRK2, a ligand with G $\beta \gamma$ blocking properties (Yevenes et al., 2003), significantly reduced the potentiation by ethanol in $\alpha 2 \beta$ GlyRs adding additional support to the notion that the $\beta$ subunit changes the functional properties of $\alpha 2$ containing GlyRs. Thus, the $\alpha 2 \beta$ conformer shows an $\alpha 1$-like pharmacological phenotype and adds new information about the molecular requirements for several clinically relevant PAMs (Mascia et al., 1996, 2000; Mihic et al., 1997; Yevenes and Zeilhofer, 2011a; McCracken et al., 2013).

\section{Implication for the Presence of $\beta$ Containing Glycine Receptors in the Upper Brain}

Although GlyRs have been routinely linked to neuronal inhibition of spinal regions (Legendre, 2001; Lynch, 2004; 

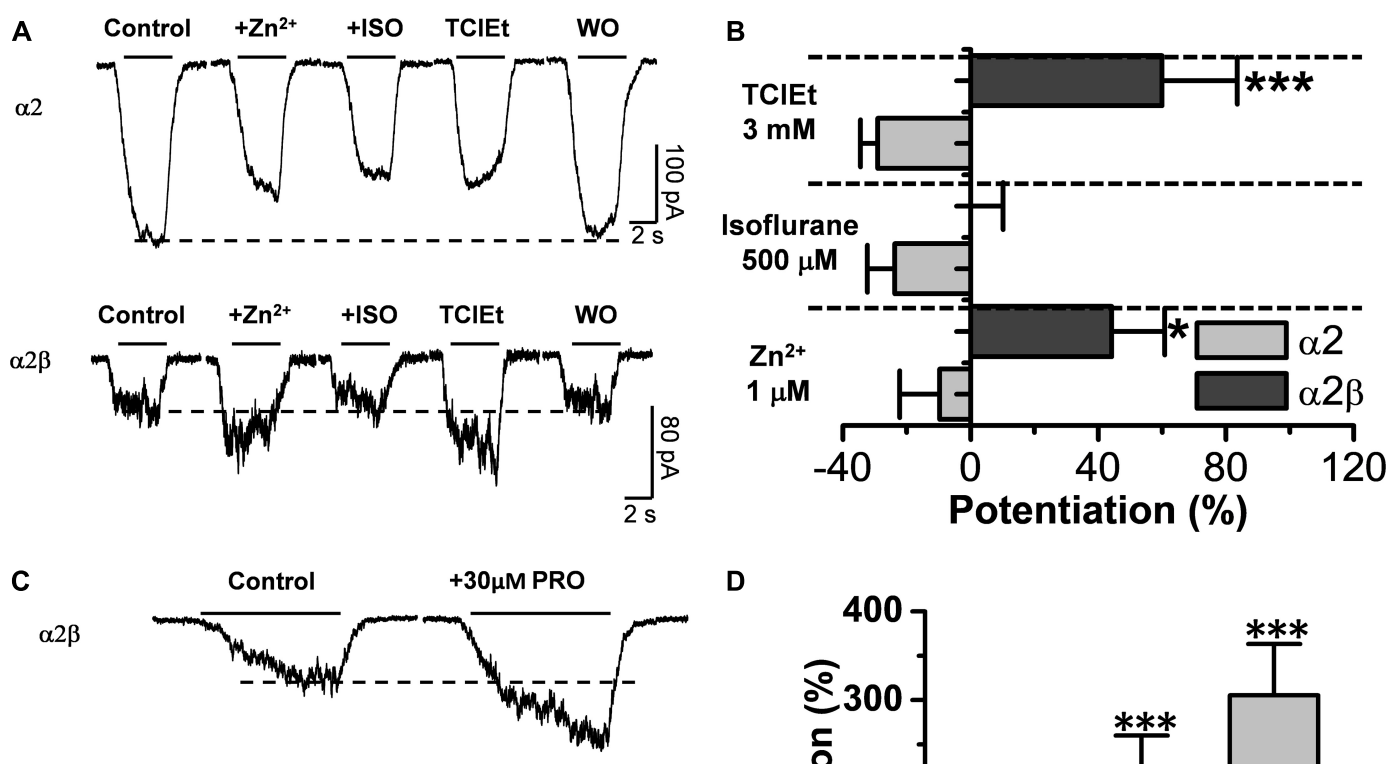

D
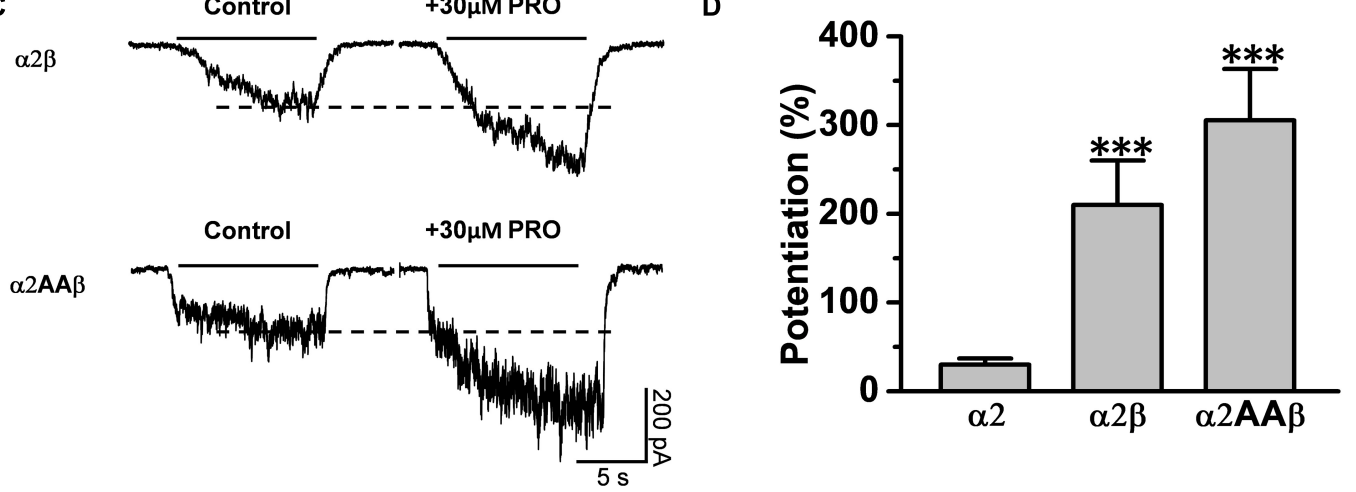

FIGURE 7 | The $\beta$ subunit confers $\alpha 1$-like pharmacological properties to $\alpha 2 \beta$ GlyRs regarding several positive allosteric modulators (PAMs). (A) Representative traces of glycine evoked currents in the presence of Zinc $(1 \mu \mathrm{M})$, isoflurane (500 $\mu \mathrm{M})$, and trichloroethanol $(3 \mathrm{mM})$ on HEK 293 cells expressing $\alpha 2$ and $\alpha 2 \beta$ GlyRs. (B) The bar graphs show the effects of co-expressing the $\beta$ subunit on the sensitivity to Zinc and TCIEt. No significant effect was found with isoflurane. (C) Glycine evoked current traces in transfected HEK 293 cells with $\alpha 2 \beta$ and $\alpha 2$ AA $\beta$ GlyRs before and after $30 \mu \mathrm{M}$ propofol application. (D) The $\beta$ subunit confers sensitivity to propofol in $\alpha 2 \beta$ and $\alpha 2 A A \beta$ expressing GlyRs. Data are mean \pm SEM. ${ }^{*} p<0.05,{ }^{* \star *} p<0.001$. Unpaired Student's $t$-test.

$$
\begin{aligned}
& \alpha_{2} \\
& \alpha_{2} \beta
\end{aligned}
$$

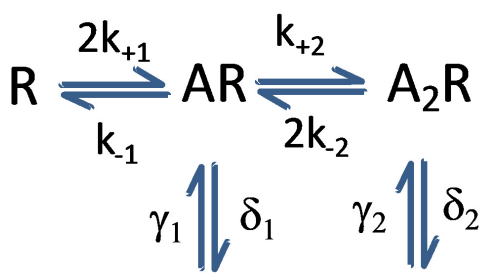

$$
\begin{aligned}
& \mathrm{AF} \rightleftharpoons \mathrm{A}_{2} \mathrm{~F} \\
& \alpha_{2} \| \beta_{2} \\
& \mathrm{~A}_{2} \mathrm{~F}^{*}
\end{aligned}
$$

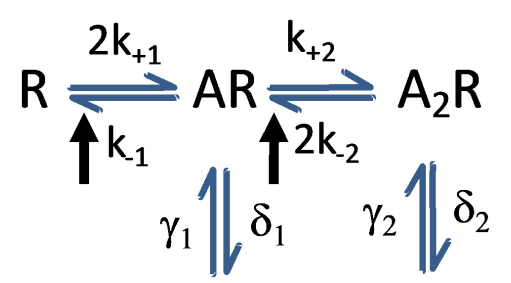

$$
\begin{aligned}
& \mathrm{AF} \rightleftharpoons \mathrm{A}_{2} \mathrm{~F} \\
& \uparrow \alpha_{2} \| \beta_{2} \\
& A_{2} F^{*}
\end{aligned}
$$

FIGURE 8 | Scheme legend. GlyR kinetic model from Krashia et al. (2011) showing possible changes in GlyR $\alpha 2$ kinetics (left) due to the expression of the $\beta$ subunit (right) and that could account for the observed differences in ethanol modulation. The proposed increase in closing rate $\alpha$ is based on the observations of decreased mean open time in $\alpha 2 \beta$ vs. $\alpha 2$ homomeric subunits, whereas the increases in glycine dissociation rates are proposed based on both the reported action of ethanol to decreased glycine unbinding rate (Welsh et al., 2009) and the lower glycine potency observed in the present study. R, receptor; A, agonist; F, "flipped" (pre-activated) state. Note that the proposed changes to the model are hypothetical and further analysis should test it in detail. 
Zeilhofer et al., 2012), more recent studies have reported the expression of $\alpha 2$ and $\alpha 3$ subunits in supra spinal regions (Salling and Harrison, 2014; Forstera et al., 2017; McCracken et al., 2017; Munoz et al., 2018, 2020; Gallegos et al., 2019) being primarily related to ethanol (Forstera et al., 2017; McCracken et al., 2017; Gallegos et al., 2019; Munoz et al., 2020) and propofol actions (Munoz et al., 2018). Using KO mice, it was suggested that $\alpha 2$ - and $\alpha 3$-containing GlyRs are important for sustaining tonic currents in the forebrain (McCracken et al., 2017) and that they might contribute to ethanol consumption (Blednov et al., 2015). These published results are interesting because while homomeric $\alpha 2$ or $\alpha 3$ GlyRs are insensitive to ethanol (Yevenes et al., 2010; Sanchez et al., 2015), any effect on animal behavior should be associated to the expression of $\beta$ subunits in $\alpha 2$ containing GlyRs, or to some receptor compensation in the $\mathrm{KO}$ mice. Recent studies provided experimental evidence supporting the expression of $\alpha 1, \alpha 2$, and $\alpha 3$ subunits in the nAc in WT mice (Forstera et al., 2017). In addition, using KI mice with the same mutation in $\alpha 2$ (K389 and R390), we demonstrated the presence of $\alpha 2 \beta$ GlyRs in accumbal neurons (Gallegos et al., 2021). Interestingly, $\alpha 2$ KI mice showed reduced sedation and increased ethanol consumption, suggesting that the $\alpha 2$ subunit is important for the ethanol potentiation of GlyRs in the adult brain (Gallegos et al., 2021). The insensitivity to ethanol of glycinergic synaptic currents in the nAc suggests that these GlyRs are mainly composed of $\alpha 1 \beta$ conformations (Munoz et al., 2018). Therefore, the broad expression of $\alpha$ and $\beta$ subunits likely play a role in several behavioral conduits and might allow for the development of pharmacotherapy based on the presence of these ethanol sensitive targets.

\section{Potential Mechanisms for the Conversion of the $\alpha 2$ Subunit Into an " $\alpha 1$-Like" Heteromeric Complex}

In an attempt to understand how the addition of the $\beta$ subunit to the $\alpha 2$ subunit was able to confer sensitivity to several PAMs, and primarily to ethanol, we can consider a previously published model for GlyRs gating (Krashia et al., 2011). The study on the $\alpha 1$ subunit showed that ethanol did not affect channel conductance or open and closed dwell times and likelihoods of the channel. On the other hand, the main effect of ethanol on $\alpha 1$ function was the enhancement of burst durations (Welsh et al., 2009) which likely reflected a decreased glycine unbinding rate(s) (k-1 and/or 2k-2), without affecting other transitions (Kirson et al., 2017), which resulted in a prolongation of burst durations without a change in mean open time (Welsh et al., 2009). The present results show that ethanol increased open probability ( $\mathrm{Po}$ ) and frequency of opening without affecting mean open time in $\alpha 1$ GlyRs, but decreased Po and frequency of opening in $\alpha 2$ GlyRs. In $\alpha 2 \beta$ GlyRs, ethanol enhanced both Po and frequency of opening in a manner similar to that found in the $\alpha 1$ subunit. On the other hand, we found that ethanol did not change the intraburst MOT or intraburst Po or burst duration in the $\alpha 2 \beta$. In addition, expression of the $\beta$ subunit in $\alpha 2$ receptors shortened mean open time to approximately that of the $\alpha 1$ subunit, indicating an increase in closing rate.
The higher affinity of $\alpha 2$ receptors for glycine compared to $\alpha 1$ receptors, which results from multiple kinetic rates rather than a simple change in unbinding rate (Lape et al., 2008; Krashia et al., 2011), may render this conformer resistant to the potentiating effects of ethanol in the absence of the $\beta$ subunit (see scheme, Figure 8).

Our results suggest that the $\beta$ subunit might rearrange the states of GlyRs changing the kinetics at the single channel level. It is possible that the $\beta$ subunit interspaced with $\alpha 2$ allows the exposure of key residues important for the conformational changes occurring after agonist binding (Lape et al., 2008; Krashia et al., 2011). They might be complementary to those recently reported that showed that shortening the IL in human GlyRs increased the open probability. The model proposed was that the IL has a modulatory action on GlyRs gating by introducing tension between TM3 and TM4 and causing them to reorient during channel opening (Ivica et al., 2020).

\section{CONCLUSION}

We describe a new role for the $\beta$ subunit for modulation by ethanol and other PAMs in $\alpha 2$ containing GlyRs. Additionally, our study supports the notion that heteromeric $\beta$ expressing GlyRs might play a crucial role in the control of excitability in upper brain regions that express $\alpha 2$ subunits.

\section{DATA AVAILABILITY STATEMENT}

The raw data supporting the conclusions of this article will be made available by the authors, without undue reservation.

\section{AUTHOR CONTRIBUTIONS}

BM and LA designed the study and wrote the manuscript. BM performed and analyzed most whole cell experiments. RP performed and analyzed the single channel studies. TM, PM, $\mathrm{CP}$, and GM-C assisted in the electrophysiological experiments. BM, GY, GM-C, and LA corrected and discussed the manuscript. LA obtained the funding to support the study, guided and discussed the experiments, and corrected the manuscript. All authors revised and approved the final version of the manuscript.

\section{FUNDING}

This work was supported by NIH RO1 AA025718 and CONICYT DPI20140008.

\section{ACKNOWLEDGMENTS}

The authors would like to thank Lauren J. Aguayo for her expert technical assistance and English revision. We appreciate the constructive comments of Lucia Sivilotti (University College London, United Kingdom). 


\section{REFERENCES}

Adermark, L., Clarke, R. B., Olsson, T., Hansson, E., Soderpalm, B., and Ericson, M. (2011). Implications for glycine receptors and astrocytes in ethanol-induced elevation of dopamine levels in the nucleus accumbens. Addict. Biol. 16, 43-54. doi: 10.1111/j.1369-1600.2010.00206.x

Aguayo, L. G., Castro, P., Mariqueo, T., Munoz, B., Xiong, W., Zhang, L., et al. (2014). Altered sedative effects of ethanol in mice with alphal glycine receptor subunits that are insensitive to Gbetagamma modulation. Neuropsychopharmacology 39, 2538-2548. doi: 10.1038/npp.2014.100

Aguayo, L. G., and Pancetti, F. C. (1994). Ethanol modulation of the gammaaminobutyric acidA- and glycine-activated $\mathrm{Cl}$ - current in cultured mouse neurons. J. Pharmacol. Exp. Ther. 270, 61-69.

Aguayo, L. G., Tapia, J. C., and Pancetti, F. C. (1996). Potentiation of the glycineactivated $\mathrm{Cl}$ - current by ethanol in cultured mouse spinal neurons. J. Pharmacol. Exp. Ther. 279, 1116-1122.

Avila, A., Nguyen, L., and Rigo, J. M. (2013a). Glycine receptors and brain development. Front. Cell. Neurosci. 7:184. doi: 10.3389/fncel.2013.00184

Avila, A., Vidal, P. M., Dear, T. N., Harvey, R. J., Rigo, J. M., and Nguyen, L. (2013b). Glycine receptor alpha2 subunit activation promotes cortical interneuron migration. Cell Rep. 4, 738-750. doi: 10.1016/j.celrep.2013.07.016

Blednov, Y. A., Benavidez, J. M., Black, M., Leiter, C. R., Osterndorff-Kahanek, E., and Harris, R. A. (2015). Glycine receptors containing alpha2 or alpha3 subunits regulate specific ethanol-mediated behaviors. J. Pharmacol. Exp. Ther. 353, 181-191. doi: 10.1124/jpet.114.221895

Borghese, C. M., Blednov, Y. A., Quan, Y., Iyer, S. V., Xiong, W., Mihic, S. J., et al. (2012). Characterization of two mutations, M287L and Q266I, in the alpha1 glycine receptor subunit that modify sensitivity to alcohols. J. Pharmacol. Exp. Ther. 340, 304-316. doi: 10.1124/jpet.111.185116

Crawford, D. K., Perkins, D. I., Trudell, J. R., Bertaccini, E. J., Davies, D. L., and Alkana, R. L. (2008). Roles for loop 2 residues of alphal glycine receptors in agonist activation. J. Biol. Chem. 283, 27698-27706. doi: 10.1074/jbc. m802384200

Eggers, E. D., O'brien, J. A., and Berger, A. J. (2000). Developmental changes in the modulation of synaptic glycine receptors by ethanol. J. Neurophysiol. 84, 2409-2416. doi: 10.1152/jn.2000.84.5.2409

Forstera, B., Munoz, B., Lobo, M. K., Chandra, R., Lovinger, D. M., and Aguayo, L. G. (2017). Presence of ethanol-sensitive glycine receptors in medium spiny neurons in the mouse nucleus accumbens. J. Physiol. 595, 5285-5300. doi: $10.1113 /$ jp273767

Fuentealba, J., Munoz, B., Yevenes, G., Moraga-Cid, G., Perez, C., Guzman, L., et al. (2011). Potentiation and inhibition of glycine receptors by tutin. Neuropharmacology 60, 453-459. doi: 10.1016/j.neuropharm.2010.10.023

Gallegos, S., Munoz, B., Araya, A., and Aguayo, L. G. (2019). High ethanol sensitive glycine receptors regulate firing in D1 medium spiny neurons in the nucleus accumbens. Neuropharmacology 160:107773. doi: 10.1016/j.neuropharm.2019. 107773

Gallegos, S., San Martin, L., Araya, A., Lovinger, D. M., Homanics, G. E., and Aguayo, L. G. (2021). Reduced sedation and increased ethanol consumption in knock-in mice expressing an ethanol insensitive alpha 2 subunit of the glycine receptor. Neuropsychopharmacology 46, 528-536. doi: 10.1038/s41386-0200689-9

Gradwell, M. A., Boyle, K. A., Callister, R. J., Hughes, D. I., and Graham, B. A. (2017). Heteromeric $\alpha / \beta$ glycine receptors regulate excitability in parvalbuminexpressing dorsal horn neurons through phasic and tonic glycinergic inhibition. J. Physiol. 595, 7185-7202. doi: 10.1113/JP274926

Grudzinska, J., Schemm, R., Haeger, S., Nicke, A., Schmalzing, G., Betz, H., et al. (2005). The beta subunit determines the ligand binding properties of synaptic glycine receptors. Neuron 45, 727-739. doi: 10.1016/j.neuron.2005.01.028

Harvey, R. J., Depner, U. B., Wassle, H., Ahmadi, S., Heindl, C., Reinold, H., et al. (2004). GlyR alpha3: an essential target for spinal PGE2-mediated inflammatory pain sensitization. Science 304, 884-887. doi: 10.1126/science.1094925

Ivica, J., Lape, R., Jazbec, V., Yu, J., Zhu, H., Gouaux, E., et al. (2020). The intracellular domain of homomeric glycine receptors modulates agonist efficacy. J. Biol. Chem. 296:100387. doi: 10.1074/jbc.RA119.012358

James, V. M., Bode, A., Chung, S.-K., Gill, J. L., Nielsen, M., Cowan, F. M., et al. (2013). Novel missense mutations in the glycine receptor $\beta$ subunit gene
(GLRB) in startle disease. Neurobiol. Dis. 52, 137-149. doi: 10.1016/j.nbd.2012. 12.001

Kirson, D., Todorovic, J., and Mihic, S. J. (2017). Single channel analysis of isoflurane and ethanol enhancement of taurine-activated glycine receptors. J. Pharmacol. Exp. Ther. 364, 70-76. doi: 10.1124/jpet.117.243840

Krashia, P., Lape, R., Lodesani, F., Colquhoun, D., and Sivilotti, L. G. (2011). The long activations of $\alpha 2$ glycine channels can be described by a mechanism with reaction intermediates ("flip"). J. Gen. Physiol. 137, 197-216. doi: 10.1085/jgp. 201010521

Lape, R., Colquhoun, D., and Sivilotti, L. G. (2008). On the nature of partial agonism in the nicotinic receptor superfamily. Nature 454, 722-727. doi: 10. 1038/nature07139

Legendre, P. (2001). The glycinergic inhibitory synapse. Cell. Mol. Life Sci. 58, 760-793. doi: 10.1007/pl00000899

Li, J., Nie, H., Bian, W., Dave, V., Janak, P. H., and Ye, J. H. (2012). Microinjection of glycine into the ventral tegmental area selectively decreases ethanol consumption. J. Pharmacol. Exp. Ther. 341, 196-204. doi: 10.1124/jpet.111. 190058

Lobo, I. A., Mascia, M. P., Trudell, J. R., and Harris, R. A. (2004). Channel gating of the glycine receptor changes accessibility to residues implicated in receptor potentiation by alcohols and anesthetics. J. Biol. Chem. 279, 33919-33927. doi: 10.1074/jbc.M313941200

Lynch, J. W. (2004). Molecular structure and function of the glycine receptor chloride channel. Physiol. Rev. 84, 1051-1095. doi: 10.1152/physrev.00042. 2003

Mascia, M. P., Mihic, S. J., Valenzuela, C. F., Schofield, P. R., and Harris, R. A. (1996). A single amino acid determines differences in ethanol actions on strychnine-sensitive glycine receptors. Mol. Pharmacol. 50, 402-406.

Mascia, M. P., Trudell, J. R., and Harris, R. A. (2000). Specific binding sites for alcohols and anesthetics on ligand-gated ion channels. Proc. Natl. Acad. Sci. U.S.A. 97, 9305-9310. doi: 10.1073/pnas.160128797

McCracken, L. M., Lowes, D. C., Salling, M. C., Carreau-Vollmer, C., Odean, N. N., Blednov, Y. A., et al. (2017). Glycine receptor $\alpha 3$ and $\alpha 2$ subunits mediate tonic and exogenous agonist-induced currents in forebrain. Proc. Natl. Acad. Sci. U.S.A. 114, E7179-E7186. doi: 10.1073/pnas.1703839114

McCracken, L. M., Trudell, J. R., Mccracken, M. L., and Harris, R. A. (2013). Zinc-dependent modulation of alpha2- and alpha3-glycine receptor subunits by ethanol. Alcohol. Clin. Exp. Res. 37, 2002-2010. doi: 10.1111/acer.12192

Mihic, S. J., Ye, Q., Wick, M. J., Koltchine, V. V., Krasowski, M. D., Finn, S. E., et al. (1997). Sites of alcohol and volatile anaesthetic action on GABA(A) and glycine receptors. Nature 389, 385-389. doi: 10.1038/38738

Molander, A., and Soderpalm, B. (2005). Glycine receptors regulate dopamine release in the rat nucleus accumbens. Alcohol. Clin. Exp. Res. 29, 17-26. doi: 10.1097/01.alc.0000150006.17168.f7

Moraga-Cid, G., Yevenes, G. E., Schmalzing, G., Peoples, R. W., and Aguayo, L. G. (2011). A Single phenylalanine residue in the main intracellular loop of alphal gamma-aminobutyric acid type A and glycine receptors influences their sensitivity to propofol. Anesthesiology 115, 464-473. doi: 10.1097/ALN. 0b013e31822550f7

Munoz, B., Gallegos, S., Peters, C., Murath, P., Lovinger, D. M., Homanics, G. E., et al. (2020). Influence of nonsynaptic alphal glycine receptors on ethanol consumption and place preference. Addict. Biol. 25:e12726. doi: 10.1111/adb. 12726

Munoz, B., Yevenes, G. E., Forstera, B., Lovinger, D. M., and Aguayo, L. G. (2018). Presence of inhibitory glycinergic transmission in medium spiny neurons in the nucleus accumbens. Front. Mol. Neurosci. 11:228. doi: 10.3389/fnmol.2018. 00228

Piro, I., Eckes, A.-L., Kasaragod, V. B., Sommer, C., Harvey, R. J., Schaefer, N., et al. (2021). Novel functional properties of missense mutations in the glycine receptor $\beta$ subunit in startle disease. Front. Mol. Neurosci. 14:745275. doi: 10.3389/fnmol.2021.745275

Qin, F. (2004). Restoration of single-channel currents using the segmental kmeans method based on hidden Markov modeling. Biophys. J. 86, 1488-1501. doi: 10.1016/S0006-3495(04)74217-4

Salling, M. C., and Harrison, N. L. (2014). Strychnine-sensitive glycine receptors on pyramidal neurons in layers II/III of the mouse prefrontal cortex are tonically activated. J. Neurophysiol. 112, 1169-1178. doi: 10.1152/jn.00714.2013 
Sanchez, A., Yevenes, G. E., San Martin, L., Burgos, C. F., Moraga-Cid, G., Harvey, R. J., et al. (2015). Control of ethanol sensitivity of the glycine receptor alpha3 subunit by transmembrane 2 , the intracellular splice cassette and C-terminal domains. J. Pharmacol. Exp. Ther. 353, 80-90. doi: 10.1124/jpet.114.221143

Sebe, J. Y., Eggers, E. D., and Berger, A. J. (2003). Differential effects of ethanol on $\mathrm{GABA}(\mathrm{A})$ and glycine receptor-mediated synaptic currents in brain stem motoneurons. J. Neurophysiol. 90, 870-875. doi: 10.1152/jn.00119.2003

Spanagel, R. (2009). Alcoholism: a systems approach from molecular physiology to addictive behavior. Physiol. Rev. 89, 649-705. doi: 10.1152/physrev.00013.2008

Welsh, B. T., Goldstein, B. E., and Mihic, S. J. (2009). Single-channel analysis of ethanol enhancement of glycine receptor function. J. Pharmacol. Exp. Ther. 330, 198-205. doi: 10.1124/jpet.109.154344

Weltzien, F., Puller, C., O'sullivan, G. A., Paarmann, I., and Betz, H. (2012). Distribution of the glycine receptor beta-subunit in the mouse CNS as revealed by a novel monoclonal antibody. J. Comp. Neurol. 520, 3962-3981. doi: 10. 1002/cne.23139

Yevenes, G. E., Moraga-Cid, G., Avila, A., Guzman, L., Figueroa, M., Peoples, R. W., et al. (2010). Molecular requirements for ethanol differential allosteric modulation of glycine receptors based on selective Gbetagamma modulation. J. Biol. Chem. 285, 30203-30213. doi: 10.1074/jbc.M110.134676

Yevenes, G. E., Moraga-Cid, G., Guzman, L., Haeger, S., Oliveira, L., Olate, J., et al. (2006). Molecular determinants for $G$ protein bg modulation of ionotropic glycine receptors. J. Biol. Chem. 281, 39300-39307. doi: 10.1074/ jbc.M608272200

Yevenes, G. E., Moraga-Cid, G., Peoples, R. W., Schmalzing, G., and Aguayo, L. G. (2008). A selective G betagamma-linked intracellular mechanism for modulation of a ligand-gated ion channel by ethanol. Proc. Natl. Acad. Sci. U.S.A. 105, 20523-20528. doi: 10.1073/pnas.0806257105

Yevenes, G. E., Peoples, R. W., Tapia, J. C., Parodi, J., Soto, X., Olate, J., et al. (2003). Modulation of glycine-activated ion channel function by G-protein betagamma subunits. Nat. Neurosci. 6, 819-824. doi: 10.1038/nn1095

Yevenes, G. E., and Zeilhofer, H. U. (2011b). Molecular sites for the positive allosteric modulation of glycine receptors by endocannabinoids. PLoS One 6:e23886. doi: 10.1371/journal.pone.0023886
Yevenes, G. E., and Zeilhofer, H. U. (2011a). Allosteric modulation of glycine receptors. Br. J. Pharmacol. 164, 224-236. doi: 10.1111/j.1476-5381.2011. 01471.x

Yu, H., Bai, X.-C., and Wang, W. (2021). Characterization of the subunit composition and structure of adult human glycine receptors. Neuron 109, 2707-2716.e6. doi: 10.1016/j.neuron.2021.08.019

Zeilhofer, H. U., Studler, B., Arabadzisz, D., Schweizer, C., Ahmadi, S., Layh, B., et al. (2005). Glycinergic neurons expressing enhanced green fluorescent protein in bacterial artificial chromosome transgenic mice. J. Comp. Neurol. $482,123-141$.

Zeilhofer, H. U., Wildner, H., and Yevenes, G. E. (2012). Fast synaptic inhibition in spinal sensory processing and pain control. Physiol. Rev. 92, 193-235. doi: 10.1152/physrev.00043.2010

Zhu, H., and Gouaux, E. (2021). Architecture and assembly mechanism of native glycine receptors. Nature doi: 10.1038/s41586-021-04022-z [Online ahead print].

Conflict of Interest: The authors declare that the research was conducted in the absence of any commercial or financial relationships that could be construed as a potential conflict of interest.

Publisher's Note: All claims expressed in this article are solely those of the authors and do not necessarily represent those of their affiliated organizations, or those of the publisher, the editors and the reviewers. Any product that may be evaluated in this article, or claim that may be made by its manufacturer, is not guaranteed or endorsed by the publisher.

Copyright (c) 2021 Muñoz, Mariqueo, Murath, Peters, Yevenes, Moraga-Cid, Peoples and Aguayo. This is an open-access article distributed under the terms of the Creative Commons Attribution License (CC BY). The use, distribution or reproduction in other forums is permitted, provided the original author(s) and the copyright owner(s) are credited and that the original publication in this journal is cited, in accordance with accepted academic practice. No use, distribution or reproduction is permitted which does not comply with these terms. 